\title{
WestVirginiaUniversity
}

THE RESEARCH REPOSITORY @ WVU

Graduate Theses, Dissertations, and Problem Reports

2017

\section{Three Essays in Real Estate Economics}

Christopher Yencha

Follow this and additional works at: https://researchrepository.wvu.edu/etd

\section{Recommended Citation}

Yencha, Christopher, "Three Essays in Real Estate Economics" (2017). Graduate Theses, Dissertations, and Problem Reports. 7005.

https://researchrepository.wvu.edu/etd/7005

This Dissertation is protected by copyright and/or related rights. It has been brought to you by the The Research Repository @ WVU with permission from the rights-holder(s). You are free to use this Dissertation in any way that is permitted by the copyright and related rights legislation that applies to your use. For other uses you must obtain permission from the rights-holder(s) directly, unless additional rights are indicated by a Creative Commons license in the record and/ or on the work itself. This Dissertation has been accepted for inclusion in WVU Graduate Theses, Dissertations, and Problem Reports collection by an authorized administrator of The Research Repository @ WVU.

For more information, please contact researchrepository@mail.wvu.edu. 


\title{
Three Essays in Real Estate Economics
}

\section{Christopher Yencha}

\author{
Dissertation submitted \\ to the College of Business and Economics \\ at West Virginia University \\ in partial fulfillment of the requirements for the degree of \\ Doctor of Philosophy in \\ Economics
}

\author{
Brad Humphreys, Ph.D., Chair \\ Amanda Ross, Ph.D. \\ Joshua Hall, Ph.D. \\ Adam Nowak, Ph.D. \\ Department of Economics \\ Paula Fitzgerald, Ph.D. \\ Department of Marketing
}
Morgantown, West Virginia
2017

Keywords: Real Estate, Machine Learning, Computer Vision, Hedonic Model, Housing Value

Copyright (c) 2017 Christopher Yencha 


\section{ABSTRACT \\ Three Essays in Real Estate Economics \\ Christopher Yencha}

This dissertation consists of three separate essays which examine the impact of home characteristics and state and local policy on home transaction prices. Chapter 1 investigates the role that pedestrian infrastructure and the walkability of the area surrounding a home has in influencing home transaction prices. Through the use of computer vision procedures to gather new data from images, Chapter 2 explores how practical and aesthetic attributes of the exterior of a home are reflected in a home's sale price. Chapter 3 estimates the impact that legalization of recreational marijuana and the subsequent establishment of marijuana dispensaries has had on home transaction prices in Denver, Colorado. 
To my mother, Lenore 


\section{Acknowledgments}

There have been many people who have walked alongside me during the last five years. They have guided me, showed me the doors that might prove useful to open, and even given me the occasional kick in the jeans I needed to push myself to be as good as I can be. I would especially like to thank Dr. Amanda Ross, Dr. Brad Humphreys, and Dr. Joshua Hall for being my three pillars of support throughout my time at West Virginia University. Without your constant presence and encouragement, the road to this achievement would have seemed lonely, indeed. I would also like to thank Dr. Paula Fitzgerald for taking me under your wing and providing unparalleled support and perspective, both about my research and simply for being a successful academic. Pui Ying Tong was my best friend and colleague throughout the last five years, and was an immediate and continual source of strength and assistance.

Finally, and without hesitation, I would to thank my mother, Lenore, to whom this dissertation is dedicated for your ceaseless support and belief in my success. Statistically, I should never have even attended college, let alone earn my Doctorate, and I believe we shattered those odds together. 


\section{Contents}

1 Walkability Measures and Residential Property Value: Evidence from Computer Vision Methods 1

1.1 Introduction . . . . . . . . . . . . . . . . . . . 1

1.2 Existing Literature . . . . . . . . . . . . . . . . . . . 4

1.3 Walk Score . . . . . . . . . . . . . . . . . . 8

1.4 Methods . . . . . . . . . . . . . . . . . . . . 11

1.4.1 Computer Vision Data Collection Technique . . . . . . . . . 11

1.4.2 Hedonic Method . . . . . . . . . . . . . . . 14

1.5 Data . . . . . . . . . . . . . . . . . . 15

1.6 Results . . . . . . . . . . . . . . . . . . . . . . . . . . 19

1.7 Conclusions and Future Research . . . . . . . . . . . . . . . 28

2 The Value of Aesthetics in Real Estate: An Application of Computer Vision Technologies $\quad 32$

2.1 Introduction . . . . . . . . . . . . . . . . . . . . 32

2.2 Existing Literature . . . . . . . . . . . . . . . . . . . . . . . . . . . . . . . . . . 33

2.3 Methods . . . . . . . . . . . . . . . . 36

2.3.1 Hedonic Method . . . . . . . . . . . . . . . 36

2.3.2 Computer Vision Data Collection . . . . . . . . . . . . . 38

2.3.3 The SVM Learning Algorithm . . . . . . . . . . . . . . . . . 39

2.3.4 Computer Vision Calibration . . . . . . . . . . . . . 43

2.4 Data Description . . . . . . . . . . . . . . . . 50

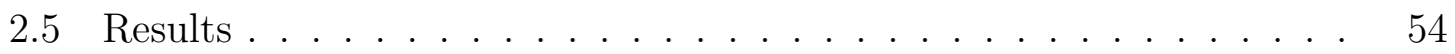

2.6 Conclusion . . . . . . . . . . . . . . . . . . 59

3 Legal Access to Recreational Marijuana as a Local Amenity $\quad 64$

3.1 Introduction . . . . . . . . . . . . . . . . 64

3.2 Backgrond and Existing Literature . . . . . . . . . . . . 66

3.3 Empirical Analysis . . . . . . . . . . . . . . . . . . . . 70

3.3.1 Data Description . . . . . . . . . . . . . . 70

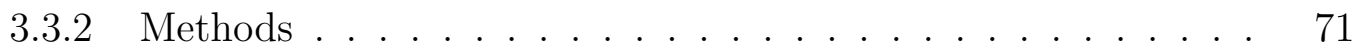

3.4 Estimation Results . . . . . . . . . . . . . . . . . . . . . . . . . 79

3.4.1 The Impact of the Establishment of Recreational Marijuana

Outlets...................... 79

3.5 Robustness Checks . . . . . . . . . . . . . . . . 80

3.5.1 Similar Outlets . . . . . . . . . . . . . . . 80

3.5.2 Counterfactual Experiment . . . . . . . . . . . . 81

3.6 Conclusion . . . . . . . . . . . . . . . . . . . . . . . . 82 


\section{List of Figures}

1 Sidewalk Panorama Example. . . . . . . . . . . . . . . . . . . . . 18

2 No Sidewalk Panorama Example. . . . . . . . . . . . . . . . . 18

3 Trees: Example of Positive and Negative Classes . . . . . . . . . . . 44

4 Effect of Training Set Size - Tree Sample - Mean Squared Error . . . 45

5 Effect of Training Set Size - Tree Sample - Mean Average Error . . . 46

6 Effect of Training Set Size - Tree Sample - Mean Average Error Squared 47

7 Effect of Training Set Size - Tree Sample - Squared Correlation Coefficient 48

8 Prediction Accuracy Response to Changes in C and $\gamma \ldots \ldots$. . . . 49

9 Denver Retail Marijuana Stores and Residential Property Sales . . . . 73

10 Price Residual Gradients for Single Family Homes . . . . . . . . . . . 76

11 Price Residual Gradients for Condominiums . . . . . . . . . . . . 77

12 Histograms of Counterfactual Opening Estimates . . . . . . . . 83 


\section{List of Tables}

1 Summary Statistics . . . . . . . . . . . . . . . . . . 16

2 Regressions for $\log$ House Price . . . . . . . . . . . . . . . 20

3 Regressions for Log House Price by Walk Score (Proximity Index) Threshold . . . . . . . . . . . . . . . . . . . . . . 23

4 Regressions for Log House Price by Access to Nearby Sidewalk . . . . 25

5 Regressions for Log House Price by Type of Neighborhood . . . . . . 27

6 Regressions for Log House Price by Access to Sidewalks and Type of Neighborhood . . . . . . . . . . . . . . . . . . . . . . . . 29

7 Summary Statistics - All Homes . . . . . . . . . . . . . . . . . . 52

8 Summary Statistics - Denver . . . . . . . . . . . . . . . . 53

9 Summary Statistics - Boulder . . . . . . . . . . . . . . . 54

10 Effect of Home Characteristics on Sale Price - All Homes . . . . . . 56

11 Effect of Home Characteristics on Sale Price - Denver . . . . . . . . 57

12 Effect of Home Characteristics on Sale Price - Boulder . . . . . . . 58

13 Effect of Home Characteristics on Sale Price - All Homes - Tree Obstruction 60

14 Effect of Home Characteristics on Sale Price - Denver - Tree Obstruction 61

15 Effect of Home Characteristics on Sale Price - Boulder - Tree Obstruction 62

16 Summary Statistics - Single Family Homes . . . . . . . . . . . . 72

17 Summary Statistics - Condominiums . . . . . . . . . . . . . 72

18 Impact of Marijuana Dispensary Establishment on Residential Property Value - Single Family Homes . . . . . . . . . . . . . . . . . 86

19 Impact of Marijuana Dispensary Establishment on Residential Property Value - Condominiums . . . . . . . . . . . . . . 87 


\section{Walkability Measures and Residential Property Value: Evidence from Computer Vision Methods}

\section{$1.1 \quad$ Introduction}

In many cities throughout the United States, considerable effort is being put into improving neighborhood walkability. For example, in Akron, OH, the director of planning and urban development is putting big, four-lane roads, originally built to serve as highways instead of neighborhood streets on "road diets." ${ }^{1}$ By "road diet," the Akron director's intention is to narrow many of the streets in Akron to accommodate the addition of bike lanes and pedestrian paths. For a variety of reasons, including urban job growth and declining crime rates, young professionals are more frequently choosing to live in cities than in the past. ${ }^{2}$ Millennials, more than any other generation, are increasingly abandoning the car for other modes of transportation such as walking, biking, and public transportation. ${ }^{3}$ By adding bike lanes and pedestrian paths, places like Akron hope to attract new and younger residents whom value these neighborhood amenities.

Pedestrian mobility is seen as having many social benefits, from reducing obesity and encouraging physical activity to mitigating vehicular congestion and pollution. For example, Owen et al. (2007) finds that walkability of a neighborhood is a factor that affects the amount of physical activity pursued by adults. The authors propose that government policy concerned with increasing the physical activity and well-being of its citizens should improve the walkability of cities. Walkable access to nearby

\footnotetext{
${ }^{1}$ http://www . crainscleveland.com/article/20160424/NEWS/160419887/putting-akronsroads-on-a-diet

${ }^{2}$ https : //www . common.com/blog/2016/07/young-professionals-and-homeownership/

${ }^{3}$ http://www .realtor .org/news-releases/2015/07/millennials-favor-walkablecommunities-says-new-nar-poll
} 
amenities also reduces the need for automobile transportation and its associated costs, freeing up funds for residents located in some areas to spend their money on other goods. McCann et al. (2000), for instance, finds that homeowners living in automobile-dependent communities spend $50 \%$ more on transportation than those living in space with more accessible land use and more transportation options.

In this paper, I consider the relationship that walkability has with residential real estate sale prices. Obtaining detailed data on walkability tends to be either immensely costly or time consuming to construct, as such primary data require the review of individual streets and walkways. Given this constraint, a considerable amount of research on the effects of walkability have relied on Walk Score® due to the ease and low cost at which the measure can be obtained. Due to the method used to calculate Walk Score, it is not exactly a measure of walkability, but more a measure of proximal access to local amenities. ${ }^{4}$ In this sense, the Walk Score index only captures a portion of what it means for a location to be walkable. For example, a walkable space not only allows access to many local establishments, but does so in a manner that provides for an adequate pedestrian experience, such as access to pedestrian amenities (i.e. benches and pedestrian crossings), the aesthetic qualities of the pedestrian path, and a feeling of safety, both from crime and traffic. By using a measure that includes these attributes, research on the subject of walkability can more confidently make claims about the impact of walkable space on any number of subjects.

I combine the Walk Score measure of proximity to establishments with information gathered from street-level images of the walkways near houses to more thoroughly describe the walkability of a given space. Computer vision procedures were used to teach computers to process and categorize images based on a number of visual characteristics of the residence and its surroundings. Computer vision analysis of

\footnotetext{
${ }^{4}$ Walk Score is calculated by analyzing walking routes to five categories of nearby amenities: grocery stores, schools, parks, restaurants, and retail outlets. I describe in detail later in the paper how this score is created.
} 
these street-level images allows for the relatively costless gathering of information about the pedestrian infrastructure outside of a given home and can supplement Walk Score's measure of walkable access to local establishments to more wholly represent the walkability of an area.

This work makes quantifiable many measures proposed in the urban planning literature concerning the nature of pedestrian walkways and contributes to research about the impacts of land use mixing on real estate markets. I find that walkability, as it pertains to both access to local amenities as well as to the quality and aesthetic properties of pedestrian paths, is an amenity reflected in house sale prices. Consistently across various specifications, ownership of private walkways and nearby access to public sidewalks are shown to increase the value of a given house in the realm of approximately $0.7 \%$ and $1 \%$, respectively. While proximity to local establishments improves housing values across most specifications, I show that when access to sidewalks is lacking, homeowners do not value being within walkable distance to amenities.

These results have important implications for urban planning, suggesting that the attraction of new businesses or the creation of public spaces like parks may not improve real estate value without adequate pedestrian infrastructure. In many cities, homeowners and developers are responsible for sidewalk maintenance and installation. Developers, who often cut costs by neglecting to build sidewalks, may wish to reevaluate their strategies as the construction of a sidewalk may lend value to the development in excess of the costs. Also, since connected and safe pedestrian paths are shown to be valued by homeowners, but installation and maintenance of a sidewalk is a private cost in many cases, it is likely that there is an underprovision of quality pedestrian pathing in cities. For this reason, the results of this paper suggest that it may be valuable for cities to solve the problem by taking sidewalk installation and maintenance under the city budget, and increasing property taxes to compensate. 


\section{$1.2 \quad$ Existing Literature}

Walkability, a measure of an area's efficiency, safety, and pleasure for pedestrian transportation, is considered a crucial aspect of urban planning and design. Contemporary urban planning places considerable emphasis on creating walkable cities, both because increased pedestrian mobility can reduce vehicular congestion and associated pollution and because efficient access to local amenities helps promote healthy lifestyles and strong communities. Indeed, municipal departments of transportation across the United States are focused intently on improving walkability. ${ }^{5}$ Litman (2003) makes an argument for the economic viability of walking, specifically citing benefits associated with walkability and cost savings, land use, economic development, and improved public health. ${ }^{6}$ The extent of support for walkability ranges from building more sidewalks and improving crosswalks to completely altering street layouts (Arth, 2009).

A considerable amount of research has been conducted demonstrating the importance of mixed land use and connectivity in improving home values. Matthews and Turnbull (2007) show that street layouts with very high connectivity affect home value, but do so differently in pedestrian oriented developments versus auto-oriented neighborhoods. Tu and Eppli $(1999,2001)$ provide some evidence that homes in very connected and walkable developments demand higher prices than those in

\footnotetext{
${ }^{5}$ See, for example, the Seattle Department of Transportation's plan at http://www.seattle.gov/transportation/pedestrian_masterplan/ or advice from the University of Delaware's Institute for Public Administration for planning and initiating programs to improve walkability within the state of Delaware at http://www.ipa.udel.edu/healthyDEtoolkit/index.html.

${ }^{6}$ While not the immediate focus of the present research, considerable work has been done to determine the effects of walkability on fitness, health, and safety in both the urban planning and public health fields. Zhu and Lee (2008) show that, while walking to school may help combat childhood inactivity and obesity, lack of safety of neighborhoods partially explains preferences against walking to school. Owen et al. (2007) use surveys of 2650 adults in high and low walkability neighborhoods to determine the frequency of walking for transportation and recreation, and determine that the walkability of a neighborhood is a factor affecting the amount of physical activity pursued. Abbott et al. (2004) find that walking is correlated with reduced risk of dementia in capable elderly men, suggesting that more walkable neighborhoods may promote a more active lifestyle and improve cognitive functions for the elderly.
} 
conventional suburban developments. Song and Knaap (2004) develop measures of mixed land use with GIS data and conclude that house prices increase with proximity to or volume of nearby public parks and commercial land uses. Walkable connectivity to a variety of local establishments appears to be a valued amenity to homeowners.

Besides access to local amenities, the quality and aesthetics of pedestrian pathing contribute to the walkability of a given community. The urban planning literature has focused substantial attention on identifying aspects of a city that make it more walkable, as well as estimating the value of efficient pedestrian mobility options to a city. Southworth (2005) refines the definition of walkability and offers six criteria urban planners can use to design walkable cities: connectivity of path network, linkages with public transportation, fine grained land use, safety, quality of pedestrian paths, and aesthetic qualities of the paths. Jaskiewicz (2000) argues that improved walkway design increases the likelihood that citizens switch from primarily automobile transportation to a walking and public transportation mix. Criteria, such as the aesthetics of a given path, highlight attributes of a walkway that are not entirely practical, but define the walking experience as much as connectivity. For this reason, measures of walkability should not stop at access and connectivity, but should also consider safety and quality of the pedestrian experience.

Methods for measuring the walkability of neighborhoods or cities are varied, including origin-destination surveys (Manaugh and El-Geneidy, 2011), walking audits such as the Pedestrian Environment Review System (PERS) (Buchanan et al., 2007), and indices such as Walk Score which intend to measure the walkability of a location based off of proximal access to amenities and public transportation offerings. ${ }^{7}$ Each measure has advantages and disadvantages inherent in the design of the tool or the expected product and uses of the measures. For instance, while the PERS systematically analyzes the pedestrian framework, focusing on walkways, public

\footnotetext{
${ }^{7}$ https://www.walkscore.com/
} 
transportation, and public spaces, it largely ignores access to privately-provided amenities such as grocery stores and restaurants. On the other hand, some walkability indices, such as Walk Score, base a measure of walkability almost solely on proximity to public transportation and local amenities, largely without regard to the actual state of walkways in the area. This is not an unusual omission, as mapping services such as Google Maps offer walking directions from one location to another which may not be pedestrian friendly. ${ }^{8}$

Cortright (2009) uses hedonic regressions to estimate the effect of the Walk Score index on home sale price. The author determines that, in a typical housing market, a one-point increase in Walk Score is associated with about a $\$ 1,000$ increase in home sales price. Alternatively, Pivo and Fisher (2011) analyze how walkability affects property values and investment returns for commercial real estate. Using the Walk Score measure, the authors conclude that a ten-point increase in the walkability index increased sales value of a property by between one and nine percent, depending on the type of property sold. Song and Knaap (2003) show that land use mix and street design partially explain home sales prices in Portland, Oregon. Particularly, the authors find that residents enjoy pedestrian accessibility to commercial space, but, unexpectedly, homebuyers are averse to proximal access to bus stops. ${ }^{9}$

Walk Score, as a measure of walkability, has been used for a variety of different studies. Rauterkus and Miller (2011) demonstrate that pedestrian proximity to local amenities generally increases residential land value so long as neighborhoods are not car dependent. Gilderbloom et al. (2015) considers how walkability affects home value, foreclosures, and crime and concludes that walkability increases home values

\footnotetext{
${ }^{8}$ In fact, Google Maps in particular realizes the weaknesses of currently offered walking directions in less built up spaces, and will state "Use caution - may involve errors or sections not suited for walking" above walking directions in locations for which the program does not know the quality of pedestrian paths.

${ }^{9}$ Research has also examined how walkable access to transportation affects house values. For more information on this subject, see, for example, Baum-Snow and Kahn (2000), McMillen and McDonald (2004), Armstrong and Rodriguez (2006), and Gibbons and Machin (2008).
} 
and reduces crime and neighborhood abandonment. Pivo (2014) shows that very high and very low Walk Scores significantly predict mortgage default risk in rental housing, where very high walkability reduces default risk and very low walkability increases defaults.

Leinberger and Alfonzo (2012) refrain from using Walk Score as their measure of walkability, opting instead to create a collection of 162 micro-scale measures, such as the presence of crosswalk markings and attractiveness of nearby landscaping, of the built environment in the Washington, D.C. metropolitan area. These measures were derived from the Irvine-Minnesota Inventory (IMI), an audit tool created to measure built environment features such as street markings and access to retail stores and restaurants (Day et al., 2006). Leinberger and Alfonzo (2012) identify ten key environmental factors empirically associated with walkability, of which only one factor reflects the information about proximity of local establishments. The other nine factors seek to explain why a given space is walkable, including urban form, pedestrian amenities, and traffic measures such as signals and traffic calming. While considerably more informative, the IMI is a costly measure to employ as it requires a researcher to physically stand along the street segment to evaluate the environment. In this sense, Walk Score, being based nearly entirely on public data, is simpler and less costly to procure.

Although most studies of home value and walkability conclude that increased walkability increases property value (Day et al., 2006; Cortright, 2009; Pivo and Fisher, 2011; Kok and Jennen, 2012), Cisneros (2015) does not find evidence that walkability, as measured by Walk Score, has an impact on home price. This non-result is not intuitive, especially in the context of the past literature which overwhelmingly suggests that homes with higher Walk Scores are more valuable. The author cites weaknesses in Walk Score's calculation of walkability, such as its ignorance of pedestrian path safety and topographic attributes, as possible reasons 
for the nonresult. If the Cisneros (2015) non-result is, indeed, driven by the omission of a more comprehensive walkability measure, then the addition of other measures, such as access to sidewalks, should improve estimation of home value.

For this reason, the objective of the present study is to more completely describe walkability, without having to resort to costly walkability audits. To do this, I supplement a measure of proximity to local establishments (Walk Score) with information gathered from images of homes and their surroundings. The intention of this data gathering exercise is to mimic the quality and accuracy of walking audits, like the PERS or IMI, while maintaining the relative costlessness and ease of use of measures like Walk Score. I demonstrate how computer vision procedures can be used to gather much of the information typically procured by walking audits and show that both pedestrian infrastructure and proximity to establishments are valued by homeowners.

\subsection{Walk Score}

Walk Score is a company that provides index measurements of walkability, bicyclefriendliness, and transit access for use by consumers searching for apartments. The company's stated mission is "to promote walkable neighborhoods." ${ }^{10}$ The premier product offered by the company, the eponymous Walk Score, calculates the walkability of any given address based on the distance to a number of nearby amenities, including education, retail, food, recreation, and entertainment establishments. The Walk Score index awards maximum points to a given category if a qualifying destination is located within a quarter mile of the address of interest. For locations further than a quarter mile, a decay function penalizes the category's score as distance increases. For locations a mile and a half out or further, the category receives no points. Upon determination of the category scores, each destination type

\footnotetext{
${ }^{10} \mathrm{https}$ // www.walkscore.com/about.shtml
} 
is given equal weight and are summed up and normalized to yield the final index, with 100 being the maximum score and 0 being the lowest. In addition to measurements of access to local establishments, Walk Score recently introduced measures of pedestrian friendliness by including information such as population density and block length in the final score of the index. ${ }^{11}$

Walk Score's wide availability is possibly the primary driver of its use; because the data used to calculate the index are widely available, the index has been calculated for a large and diverse number of cities and locations. However, the measure does not come without problems. The principal weakness of the index is that it does not reflect the quality of the walking experience between the address and destinations. First, walking distances to the nearest establishment are calculated using the Euclidean distance from the address to the establishment. Walk Score effectively ignores topographic impediments that might hinder pedestrian access along the straight-line route. Even in a gridiron street plan, such as that found in New York or Chicago, when the destination lies on a different street from the starting point, the Walk Score index plots a pedestrian path through buildings, which is not the path pedestrians will take. Even worse, in cities with less regular street plans or those for which the topography has shaped the layout of the city, Euclidean distances between addresses and local amenities rarely represent the actual path taken by the pedestrian.

While Walk Score has recently attempted to rectify its weakness by including measures such as population density and block length into the calculation of the index, the measure still has a ways to go in representing the pedestrian experience. The index, as it stands, does not distinguish between pedestrian paths that may or may not have pedestrian amenities such as sidewalks, curb cuts, and street furniture, nor does

\footnotetext{
${ }^{11} \mathrm{How}$ these measures of pedestrian friendliness impact the final Walk Score is unclear based upon the methods presented on the Walk Score webpage at https://www.walkscore.com/methodology.shtml. Suffice it to say, little research has used Walk Score as an indicator for pedestrian friendliness, opting to focus on its power as a measure of pedestrian accessibility.
} 
Walk Score include a measure of pedestrian safety, whether from traffic or crime, along a given route. These omissions make the Walk Score index more of a measurement of the presence and variety of non-residential land-use than a comprehensive measure of walkability.

Another limitation of Walk Score stems from how the index is calculated. Walk Score weights all categories of local establishments equally. This means, for instance, that access to parks and recreation is considered of equal value as access to grocery stores and restaurants. While this weighting might reflect the preferences of some residents, it leaves no room for the possibility that people choose to live in different places for different reasons. Additionally, some establishment mixes might appeal more to visitors and tourists than to residents. For example, while walkable access to restaurants and entertainment might be crucial to attracting tourism, these establishments may not as valuable to residents without cars as access to grocery stores or other consumer-oriented businesses like dry cleaning. Walk Score also does not distinguish between different classes of establishments within categories: the nearest convenience store is counted the same as the nearest grocery store for access to food. An address may receive a very high score for the "food" category for a nearby convenience store, even though residents have to drive to a grocery store to procure most food items. Such an undiscriminating weighting scheme may, therefore, overweight the walkability of a particular property because of access to local establishments that do not actually provide all of the expected needs of the resident.

While Walk Score purports to be a measure of walkability, the index is constructed and weighted mainly by the Euclidean distances between a given address and classes of local destinations, such as parks and restaurants. The index ignores the pedestrian infrastructure of the prescribed route, possibly suggesting pedestrians would need to walk along roads without sidewalks. While limited in its capacity as the sole measure of walkability, Walk Score is still a useful measure of access to and the variety of local 
amenities. In combination with measures typically included in walkability audits, such as access to pedestrian pathways and protection from traffic, Walk Score can more comprehensively describe the walking experience of a given space. While these additional measures have been quite costly to collect in the past, I show in the next section that computer vision procedures can be used to relatively effortlessly acquire more information about the pedestrian experience.

\subsection{Methods}

\subsubsection{Computer Vision Data Collection Technique}

Machine learning is a set of statistical tools designed for the analysis of complex datasets, with particular emphasis on prediction and classification. Machine learning is the product of multidisciplinary work between statisticians and computer scientists, with practical applications in many fields, including genetics and genomics, as well as in industry. This includes textual analysis, which has become increasingly popular in the fields of economics and finance (e.g. Loughran and McDonald (2011), Taddy (2013))

In addition to gathering information from text, researchers in the social sciences have also begun to collect data from images to answer relevant research questions. ${ }^{12}$ Computer vision describes the methods of teaching computers to obtain, process, and understand images. The data used in computer vision are images, which are exceptionally high-dimensional data, typically of real world places, people, and objects, to provide insight into the source or construction of the subject of the image, usually in the form of symbolic or numeric outcomes.

As a field, computer vision has focused on teaching computers to not only see

\footnotetext{
${ }^{12}$ Studies in economics have used image data to discuss the impact of beauty on economic outcomes, among other subjects (e.g. Mobius and Rosenblat (2006), Hamermesh (2006)). Naik et al. $(2015,2016)$ use computer vision procedures to gather information about perceptions of safety from images of cityscapes.
} 
images, but to understand the subject of the image - a seemingly far-fetched goal, but one that is both important and attainable, as continued research and application of the techniques leads to greater insight into how machines can be taught to process images. ${ }^{13}$ Private market applications of computer vision include motion estimation and object detection (Felzenszwalb et al., 2010; Mohan et al., 2001), and technologies designed to detect dangerous road conditions and cracked surfaces for self-driving cars (Levinson et al., 2011).

Additionally, computer vision techniques are being widely adopted and used in economics, particularly in urban and regional research. One recent paper used computer vision to quantify the appearance of streetscapes from survey data about a respondent's evaluation of the perceived safety of urban space to train their computer vision algorithm (Naik et al., 2016). The authors show that their measure of urban safety derived from the computer vision algorithm is correlated with many socio-demographic characteristics of a given city. Another recent project uses computer vision techniques to quantify the change in the physical appearance of streetscapes in cities (Naik et al., 2015). Naik et al. (2015) use this measure of urban change to explore whether demographic and economic changes precede, follow, or occur simultaneously with changes in the appearance of a city, finding some empirical support for tipping and filtering theories.

For classification of images of homes, I use support vector machines (SVM) as this algorithm is comparatively simple to use, easy to calibrate, and accurate. A SVM is a supervised machine learning algorithm with application in classification. Essentially, the SVM plots training data and then draws a line that best separates the training observations. When new (test) data are plotted, the SVM outputs which side of the

\footnotetext{
${ }^{13}$ The most prolific project aimed at teaching machines to understand and express what objects in images are is likely Li Fei-Fei's 2015 TED Talk "How We're Teaching Computers to Understand Pictures." The notion of teaching computers to understand instead of just process information has been one of the more exciting attributes of recent machine learning research. Events like IBM's Watson's appearance on the popular trivia gameshow, Jeopardy, have allowed for recent advances in machine learning to capture the public's attention and imagination.
} 
line each test observations falls within. Given a small subset of training data which the trainer has already categorized, the SVM can use the information it has gathered from analyzing patterns in the training set to categorize new data. In analyzing the training set, the SVM algorithm is capable of generating the optimal hyperplane that separates categories in the training data while maximizing the margin between the most similar, but categorically different, observations.

Analysis begins with training data consisiting of some $N$ pairs of classifications, $\left(x_{1}, y_{1}\right),\left(x_{2}, y_{2}\right), \ldots,\left(x_{N}, y_{N}\right) . x_{i}$ is assumed to belong to the set $\mathbb{R}^{p}$ and $y_{i}$ can take class values -1 and 1 . A separating hyperplane can be defined as:

$$
f(x)=\beta_{0}+x^{T} \beta=0
$$

and the classification rule

$$
G(x)=\operatorname{sign}\left[x^{T} \beta+\beta_{0}\right]
$$

The goal of SVM is to find a hyperplane that maximizes the margin between the two classes in the training data. An optimization problem expressing this goal can be written as

$$
\max _{\beta, \beta_{0},\|\beta\|=1} M \text { s.t. } y_{i}\left(x_{i}^{T} \beta+\beta_{0}\right) \geq M, \quad i=1, \ldots N
$$

where $M$ is the distance from the decision boundary and the edge of the margin.

The defining quality of SVM, as opposed to naive linear classifiers, is that it can handle observations that overlap in the feature space. A budget constraint is introduced to allow for observations to be on the wrong side of the classifier, with such observations penalized in the optimization problem. To incorporate this penalty, I modify the constraint in the optimization problem as follows:

$$
y_{i}\left(\beta_{0}+x_{i}^{T} \beta\right) \geq M\left(1-\xi_{i}\right)
$$


where $\forall_{i}, \quad \xi_{i} \geq 0, \quad \sum_{i=1}^{N} \xi_{i} \leq K$, where $\mathrm{K}$ is some chosen constant, and $\xi_{i}=$ $\left.\xi_{1}, \xi_{2}, \ldots, \xi_{N}\right)$ are the slack variables, used to describe the relative distance from the decision boundary by which a given training observation overlaps the wrong classification region (Smith, 1968). In very noisy data, such as photos for which the image of a given object may be taken from different angles or distances, the training data may not be linearly separable. The standard approach for dealing with a training set that is not linearly separable is to allow a few mistakes during classification. When a mistake is allowed for training observation $i$, we pay some positive costs, $\xi_{i}$, dependent upon how far away the observation was from meeting the margin requirement, or the constraint in Equation 3. The goal of introducing the slack variables into the objective fnction with high-dimensional data is to allow for solutions to the SVM while maintaining high classification accuracy.

SVM as a tool in the statistical learning and machine learning toolboxes has earned its place due to its relative accuracy, light computational load, practical interpretation, and breadth of applications. In the social sciences, this tool can be used accurately and with relative ease, allowing for classification of images based on recognition of attributes of interest. ${ }^{14}$

\subsubsection{Hedonic Method}

Rosen (1974) posited that a residential property can be thought of as composite good, the price of which can be described as a function of the characteristics of the property, including the characteristics of the house (i.e. number of bedrooms, square footage of the home, etc.) and its surroundings (i.e. access to schools, wealth of the neighborhood, etc.). In this sense, the sale price of a residential property reflects the sum of the implicit prices of each part of the composite good. Hedonic models have been used to analyze a variety of different topics in real estate economics, including the

\footnotetext{
${ }^{14}$ Further reading on the subject and use of classification algorithms can be found in Friedman et al. (2001).
} 
impact of airport noise pollution on residential home sale prices (Nelson, 2004; Pope, 2008a), access to parks and the threat of crime on property value (Troy and Grove, 2008), and neighborhood safety (Linden and Rockoff, 2008; Pope, 2008c; Caudill et al., 2015). Consequently, it is reasonable to assume that access to nearby amenities and the quality of pedestrian infrastructure may reflect the implicit price of walkability.

A standard log-linear econometric approximation of the hedonic housing price model emphasizing the estimation of walkability of a residential property is given by:

$$
\ln (\text { price })_{i j}=\beta X_{i j}+\gamma W_{i}+\theta_{M S A}+\epsilon_{i j}
$$

where $\ln (\text { price })_{i j}$ is the natural logarithm of the sale price of the $i$ th house in the $j$ th census block, $X_{i j}$ is a vector of house and neighborhood characteristics unrelated to walkability, $W_{i}$ is a vector of measures reflecting the walkability of the space about a given house, $\theta_{M S A}$ are MSA fixed-effects, and $\epsilon_{i j}$ is a stochastic error term. Variables measring the walkability around a given hose include measures of proximity to nearby establishments and various dummy variables gathered from calibrated computer vision routines taught to classify images of homes based on the presence of nearby sidewalks and street lighting.

\subsection{Data}

To conduct the analysis, I use data on home price transactions and housing attributes in Ohio for the year 2000. The data has been used by Brasington and Haurin (2006), Brasington (2007), Brasington and Hite (2008), and Hall (2017). House prices from this dataset encompass home transactions from seven Ohio cities: Akron, Cincinnati, Cleveland, Columbus, Dayton, Toledo, and Youngstown. The data contains a total of 59,352 observations for which there is no missing information about the housing attributes. The house characteristics include the number of 
bedrooms and bathrooms, building and lot size in square feet, and the age of the home. There are also dummy variables for the presence of a fireplace, central air conditioning and heating, whether the house has a deck, and whether or not a home is a single story. Besides variables describing the structure of a home, socio-demographic variables, such as the percentage of the census block that is white and the median household income of the census block, are included to control for variation between neighborhoods. Variable definitions and summary statistics are reported in Table 1.

Table 1: Summary Statistics

\begin{tabular}{lcccc}
\hline \hline Statistic & Mean & St. Dev. & Min & Max \\
\hline Price & 128,904 & 102,250 & 30,000 & $8,706,000$ \\
$\ln$ (Price) & 11.599 & 0.552 & 10.309 & 15.980 \\
AC & 0.320 & 0.467 & 0 & 1 \\
Fireplace & 0.467 & 0.581 & 0 & 7 \\
Bedrooms & 1.430 & 0.597 & 0 & 9 \\
Bathrooms & 0.435 & 0.533 & 0 & 8 \\
Age & 45 & 31 & 0 & 200 \\
Building SqFt (100's SqFt) & 16 & 7 & 0 & 353 \\
Lot Size SqFt (1000's SqFt) & 14 & 37 & 0 & 3,485 \\
Deck & 0.084 & 0.278 & 0 & 1 \\
Pct White & 81.588 & 23.808 & 0 & 100 \\
Ethnic Heterogeneity & 0.119 & 0.110 & 0 & 0.968 \\
Pct No HS Diploma & 14.724 & 10.798 & 0 & 76.531 \\
Pct Blue Collar & 30.054 & 13.267 & 0 & 100 \\
Median Income & 50,350 & 21,820 & 6,136 & 200,001 \\
Offenses & 74.45 & 48.11 & 0.97 & 735.34 \\
Proximity & 34.047 & 21.930 & 0 & 97 \\
Walkway & 0.471 & 0.499 & 0 & 1 \\
Sidewalk & 0.358 & 0.479 & 0 & 1 \\
Lights & 0.552 & 0.497 & 0 & 1 \\
Curb & 0.629 & 0.483 & 0 & 1 \\
\hline
\end{tabular}

Walkability is a multi-faceted construct, wherein access to nearby amenities is only a fraction of the pedestrian experience. To obtain a comprehensive measure of the walkable space around a given home, a variety of measures are used in this analysis. Walk Score is used to indicate the presence of local amenities. As discussed in more 
detail above, Walk Score is calculated by analyzing walking routes to five categories of nearby amenities. Up to 20 points are awarded to a location for each category, dependent upon the distance from the location to the amenity. While Walk Score does not entirely describe walkability, it serves as a useful measure of proximity to amenities.

Computer vision technologies are also used to enhance the Walk Score measure and to describe more fully how walkable an area is. To obtain these measures, a program was written to access Google Street View using the addresses and geocoordinates of each home transaction. The program sends a query to Google Street View, retrieves an image of the face of the home, as well as images of the surroundings of a home at street side at 90 degree intervals. The program then resizes images from the default 640x400 pixels to 200x200 pixel, converts the images to grey-scale JPEG files, and saves the images. Images of a single home and its surroundings were stitched together afterwards to create panoramas, a combined 800x200 pixel image.

Pedestrian pathways, like sidewalks, are crucial to include in conversations of walkability as they provide safe and convenient pedestrian access to destinations. In teaching the computer to recognize images of homes and surroundings that possess sidewalks, a training set was created. The training set contains two collections of images: one which collects images of homes and their surroundings lacking sidewalks within the frame, and another that possesses images of homes and surroundings that have sidewalks in the frame. An example of a panorama of a home with sidewalks can be seen in Figure 1 and of a home without sidewalks in Figure $2 .{ }^{15}$

Attributes collected from the home images reflect measures of walkability discussed in the existing literature to supplement measures of proximity of establishments in quantifying walkability (Southworth, 2005; Ewing and Handy, 2009; Hajrasouliha and Yin, 2015). A computer vision algorithm was calibrated to classify observations for

\footnotetext{
${ }^{15}$ The example panorama figures are displayed in color and larger resolution for the reader's convenience. All panorama images used in the study are grey-scale and measure 800x200 pixels.
} 


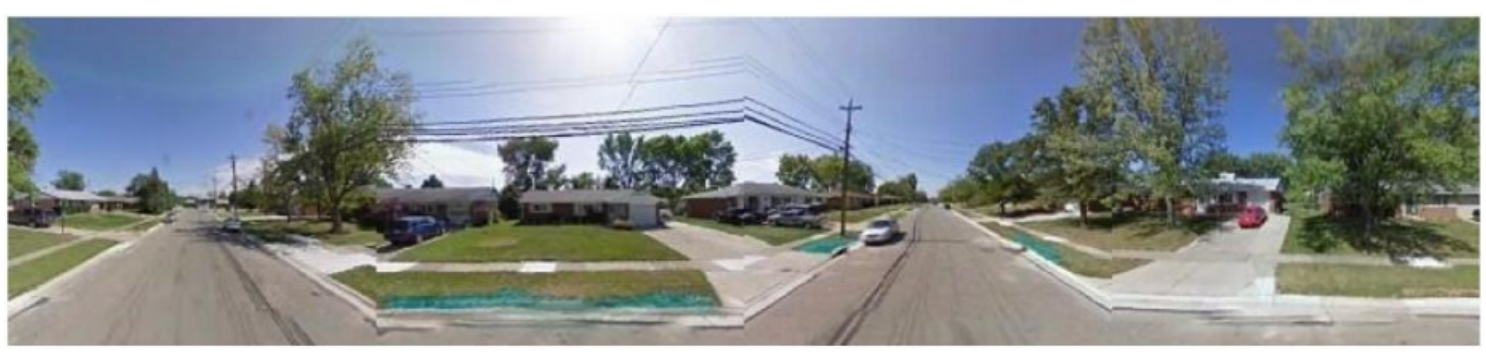

Figure 1: Sidewalk Panorama Example

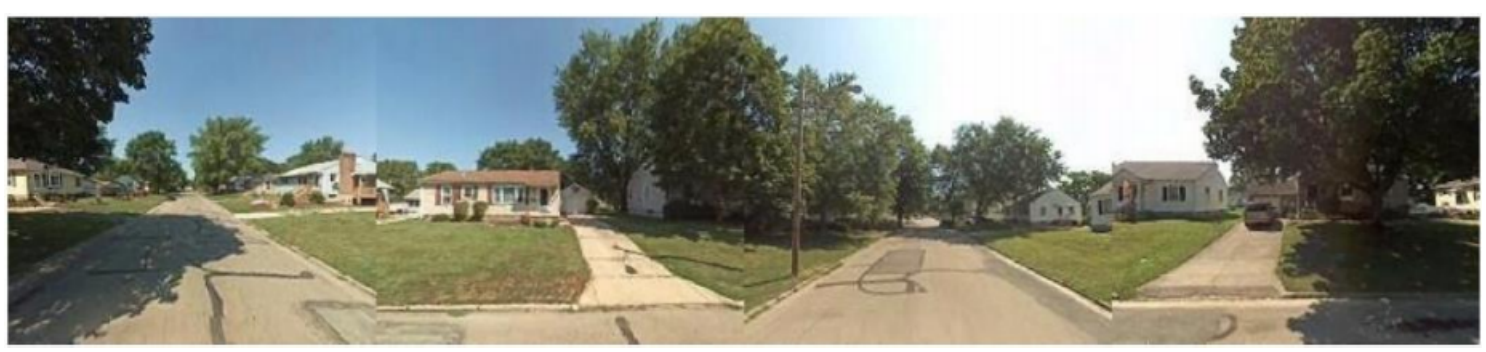

Figure 2: No Sidewalk Panorama Example

which sidewalks are visible outside of a given home. ${ }^{16}$ To quantify access to and the connectivity of the pedestrian network, observations were also classified based on whether or not a house has a walkway which leads from the front door to the sidewalk or adjacent street. ${ }^{17}$ In addition to approximating connectivity of the path network to individual homes, the walkway measure might be suggestive of the home owner's or builder's perception of the walkability of a given space, possibly shedding light on the practical and functional attributes of the nearby pedestrian network. Measures accounting for the connectivity of the path network are important to include in the hedonic equation alongside a measure of proximity to nearby establishments to fully describe the walkability of a given space.

Other than connectivity of a house, safety is also a concern of pedestrians (Southworth, 2005; Zhu and Lee, 2008). To generate measures of safety, computer vision algorithms classified houses based on the presence of nearby streetlights and

\footnotetext{
${ }^{16}$ LibSVM, a library of SVMs in the C++ language, was used for all SVM calibration and implementation (Chang and Lin, 2011).

${ }^{17}$ Note that, while a panorama was used to investigate the presence of nearby sidewalks, for instance, the nature of the walkway variable does not necessitate a panorama. As such, only a 200x200 pixel image of the home was used for identification of walkways.
} 
curb edging separating the street from possible pedestrian paths (without regard of the presence of sidewalks, as the path network in less pedestrian-friendly space may not include sidewalks). Streetlights make a pedestrian path less hazardous to navigate at night. Additionally, because streetlights are built and maintained by the municipality, the presence of streetlights along a pedestrian path might indicate the frequency with which pedestrians use the paths. Curbs, by construction, discourage automobiles from entering pedestrian paths. Low-speed traffic curbs may help channel automobile traffic and keep automobiles from accidentally veering off path. Even with high-speed traffic where typical curbs in the United States would have little power to repel an automobile that hits it, curbs may still provide pedestrians with a feeling of safety and are likely preferred.

\subsection{Results}

Table 2 presents the baseline estimates of the hedonic price regression for house structural and neighborhood characteristics, including measures of walkability. Column (1) contains the housing attributes typically included in hedonic price models of residential real estate sales, and the estimated coefficients have the expected signs. For instance, more bedrooms, more living space, and the presence of a fireplace increase the sale price of a house, while an older house is associated with lower prices. Column (2) adds the census control variables at the block level, such as percentage white, percentage without a high school diploma, and median household income in the census block. These socio-demographic controls are highly significant and take the expected signs. The addition of these socio-demographic controls do not alter the signs of the coefficients on the housing attributes.

In columns (3) and (4), I expand upon the structural and neighborhood characteristics of the sale price of the house to see which measures of walkability affect house prices. In column (3), I add only the Walk Score index of proximity 
Table 2: Regressions for Log House Price

\begin{tabular}{|c|c|c|c|c|}
\hline & \multicolumn{4}{|c|}{ Dependent variable: } \\
\hline & \multicolumn{4}{|c|}{$\ln ($ Price $)$} \\
\hline & $(1)$ & (2) & (3) & (4) \\
\hline $\mathrm{AC}$ & $\begin{array}{l}0.064^{*} \\
(0.004)\end{array}$ & $\begin{array}{l}0.033^{* *} \\
(0.003)\end{array}$ & $\begin{array}{l}0.032^{* *} \\
(0.003)\end{array}$ & $\begin{array}{l}0.033^{* *} \\
(0.003)\end{array}$ \\
\hline Fireplace & $\begin{array}{l}0.140^{* *} \\
(0.003)\end{array}$ & $\begin{array}{l}0.061^{* *} \\
(0.002)\end{array}$ & $\begin{array}{l}0.061^{* *} \\
(0.002)\end{array}$ & $\begin{array}{l}0.060^{* *} \\
(0.002)\end{array}$ \\
\hline Bedrooms & $\begin{array}{l}0.114^{* *} \\
(0.003)\end{array}$ & $\begin{array}{l}0.088^{* *} \\
(0.003)\end{array}$ & $\begin{array}{l}0.089^{* *} \\
(0.003)\end{array}$ & $\begin{array}{l}0.089^{* *} \\
(0.003)\end{array}$ \\
\hline Bathrooms & $\begin{array}{l}0.102^{* *} \\
(0.003)\end{array}$ & $\begin{array}{l}0.066^{* *} \\
(0.003)\end{array}$ & $\begin{array}{l}0.066^{* *} \\
(0.003)\end{array}$ & $\begin{array}{l}0.066^{* *} \\
(0.003)\end{array}$ \\
\hline Age & $\begin{array}{c}-0.004^{* *} \\
(0.0001)\end{array}$ & $\begin{array}{l}-0.002^{* *} \\
(0.00005)\end{array}$ & $\begin{array}{c}-0.002^{* *} \\
(0.0001)\end{array}$ & $\begin{array}{c}-0.002^{* *} \\
(0.0001)\end{array}$ \\
\hline Building SqFt & $\begin{array}{c}0.033^{* *} \\
(0.0003)\end{array}$ & $\begin{array}{c}0.028^{* *} \\
(0.0003)\end{array}$ & $\begin{array}{c}0.028^{* *} \\
(0.0003)\end{array}$ & $\begin{array}{c}0.028^{* *} \\
(0.0003)\end{array}$ \\
\hline Lot Size SqFt & $\begin{array}{c}0.001^{* *} \\
(0.00004)\end{array}$ & $\begin{array}{c}0.001^{* *} \\
(0.00003)\end{array}$ & $\begin{array}{c}0.001^{* *} \\
(0.00003)\end{array}$ & $\begin{array}{c}0.001^{* *} \\
(0.00003)\end{array}$ \\
\hline Deck & $\begin{array}{l}0.095^{* *} \\
(0.005)\end{array}$ & $\begin{array}{l}0.059^{* *} \\
(0.004)\end{array}$ & $\begin{array}{l}0.058^{* *} \\
(0.004)\end{array}$ & $\begin{array}{l}0.058^{* *} \\
(0.004)\end{array}$ \\
\hline Proximity & - & - & $\begin{array}{l}0.0004^{* *} \\
(0.0001)\end{array}$ & $\begin{array}{l}0.0004^{* *} \\
(0.0001)\end{array}$ \\
\hline Walkway & - & - & - & $\begin{array}{l}0.007^{* *} \\
(0.002)\end{array}$ \\
\hline Sidewalk & - & - & - & $\begin{array}{l}0.010^{* *} \\
(0.003)\end{array}$ \\
\hline Lights & - & - & - & $\begin{array}{l}0.0002 \\
(0.002)\end{array}$ \\
\hline Curb & - & - & - & $\begin{array}{l}-0.003 \\
(0.002)\end{array}$ \\
\hline Census Controls? & $\mathrm{N}$ & Y & Y & Y \\
\hline MSA Dummies? & $\mathrm{Y}$ & $\mathrm{Y}$ & $\mathrm{Y}$ & $\mathrm{Y}$ \\
\hline Observations & 59,352 & 59,352 & 59,285 & 59,285 \\
\hline $\mathrm{R}^{2}$ & 0.664 & 0.754 & 0.754 & 0.754 \\
\hline
\end{tabular}

Note: ${ }^{*}$ and ${ }^{* *}$ indicate significance at the $5 \%$ and $1 \%$ levels, respectively. Census controls, including \% White, Ethnic Heterogeneity, \% No Highschool Diploma, \% Blue Collar Jobs, Median Household Income, and Per Capita Criminal Offenses are significant at the $1 \%$ level. 
to amenities, as has been commonly used as a measure of walkability in past studies. Unsurprisingly, the estimated variables reflecting proximal access to local establishments and pedestrian infrastructure such as walkways and sidewalks are positive and significant. A ten-point increase in Walk Score is associated with a $0.4 \%$ increase in house sale price, well below the results for office and retail property real estate sales of about $0.9 \%$ (Pivo and Fisher, 2011). It would appear from this result that homeowners value living near to local establishments, although the value of proximity to amenities for residents in this sample is lower than in other studies. The difference in the effect of proximity to amenities on property value between residential and commercial real estate may be attributable to increased foot traffic or agglomeration economies, although the effect may be tempered by increased competition in spaces with higher Walk Scores.

In column 4, I supplement the measure of proximity to amenities with data gathered from the computer vision analysis of street-level images about pedestrian walkways. The estimated coefficient for proximity to local amenities, or Walk Score, maintains the expected sign and magnitude. This implies that the variance in home value explained by proximity to establishments and that explained by other measured pedestrian amenities is quite different.

Nearby access to sidewalks is associated with approximately a $1 \%$ increase in house sale price, and a walkway from the front of a home to the sidewalk or adjacent street is associated with about a $0.7 \%$ increase in sale price. Street lighting and raised curbs, possible indicators for safety of the pedestrian path, do not seem to impact home sale price. While previous research, especially in the urban planning literature, discussed the value of safety measures such as these in improving the pedestrian experience, I do not find evidence initially that home value reacts to these measures of pedestrian safety. All other controls from the baseline model continue to have the expected signs.

Table 3 considers the value of the pedestrian experience on home sale prices at 
varying levels of access to local establishments. Because sidewalks are used as a means for pedestrians to traverse the distance between locations, one would not expect for pedestrian pathing to be very valuable in space for which there are few nearby destinations. Column 1 restricts the sample to only include houses with non-zero Walk Scores, column 2 for houses with Walk Scores greater than 20, etc. A Walk Score of zero indicates that no local establishment measured by Walk Score, such as a restaurant or grocery store, exists within a mile and a half from a house.

In restricting the sample to exclude homes near few walkable destinations, I further isolate the importance of pedestrian paths for houses near local establishments. As houses with low Walk Scores are progressively omitted from the regressions, the coefficients on Walk Score, Walkway, and Sidewalk generally increase. This is expected: marginal increases in access to local amenities are going to be more valuable to households that expect to walk to accomplish many of their errands than those who only walk to accomplish a single errand. Additionally, pedestrian infrastructure matters more to those who regularly walk to access local amenities.

Given that the effect of access to local establishments on house sale price seems to decline when more homes without many local establishments within a walkable distance are included, it is crucial to investigate if access to establishments matters when there is no pedestrian pathing near a given home. As discussed above, Walk Score has been used as a sole measure of walkability in a number of previous studies on residential real estate transactions. However, the attenuating effect of Walk Score on residential property prices as homes with lower Walk Scores are excluded suggest that proximal access to local amenities may have varying effects on different subsamples of the data.

Without adequate pedestrian infrastructure like sidewalks and streetlights, living at walkable distances to nearby establishments may not be valuable to homeowners. To test if this is true, Table 4 presents regression results where the sample has been 
Table 3: Regressions for Log House Price by Walk Score (Proximity Index) Threshold

\begin{tabular}{|c|c|c|c|c|}
\hline & \multicolumn{4}{|c|}{ Dependent variable: } \\
\hline & \multicolumn{4}{|c|}{$\ln$ (Price) } \\
\hline & (1) & $(2)$ & (3) & $(4)$ \\
\hline $\mathrm{AC}$ & $\begin{array}{l}0.034^{* *} \\
(0.003)\end{array}$ & $\begin{array}{l}0.057^{* *} \\
(0.004)\end{array}$ & $\begin{array}{l}0.074^{* *} \\
(0.006)\end{array}$ & $\begin{array}{l}0.089^{* *} \\
(0.008)\end{array}$ \\
\hline Fireplace & $\begin{array}{l}0.061^{* *} \\
(0.002)\end{array}$ & $\begin{array}{l}0.066^{* *} \\
(0.003)\end{array}$ & $\begin{array}{l}0.072^{* *} \\
(0.004)\end{array}$ & $\begin{array}{l}0.073^{* *} \\
(0.005)\end{array}$ \\
\hline Bedrooms & $\begin{array}{l}0.090^{* *} \\
(0.003)\end{array}$ & $\begin{array}{l}0.087^{* *} \\
(0.004)\end{array}$ & $\begin{array}{l}0.091^{* *} \\
(0.005)\end{array}$ & $\begin{array}{l}0.107^{* *} \\
(0.006)\end{array}$ \\
\hline Bathrooms & $\begin{array}{l}0.068^{* *} \\
(0.003)\end{array}$ & $\begin{array}{l}0.076^{* *} \\
(0.003)\end{array}$ & $\begin{array}{l}0.089^{* *} \\
(0.005)\end{array}$ & $\begin{array}{l}0.097^{* *} \\
(0.006)\end{array}$ \\
\hline Age & $\begin{array}{c}-0.002^{* *} \\
(0.0001)\end{array}$ & $\begin{array}{c}-0.002^{* *} \\
(0.0001)\end{array}$ & $\begin{array}{c}-0.002^{* *} \\
(0.0001)\end{array}$ & $\begin{array}{c}-0.001^{* *} \\
(0.0001)\end{array}$ \\
\hline Building SqFt & $\begin{array}{c}0.027^{* *} \\
(0.0003)\end{array}$ & $\begin{array}{c}0.026^{* *} \\
(0.0003)\end{array}$ & $\begin{array}{c}0.022^{* *} \\
(0.0004)\end{array}$ & $\begin{array}{l}0.019^{* *} \\
(0.001)\end{array}$ \\
\hline Lot Size SqFt & $\begin{array}{c}0.001^{* *} \\
(0.00004)\end{array}$ & $\begin{array}{c}0.001^{* *} \\
(0.0001)\end{array}$ & $\begin{array}{c}0.002^{* *} \\
(0.0002)\end{array}$ & $\begin{array}{c}0.003^{* *} \\
(0.0003)\end{array}$ \\
\hline Deck & $\begin{array}{l}0.057^{* *} \\
(0.004)\end{array}$ & $\begin{array}{l}0.065^{* *} \\
(0.006)\end{array}$ & $\begin{array}{l}0.070^{* *} \\
(0.008)\end{array}$ & $\begin{array}{l}0.076^{* *} \\
(0.010)\end{array}$ \\
\hline Proximity & $\begin{array}{c}0.001^{* *} \\
(0.0001)\end{array}$ & $\begin{array}{c}0.001^{* *} \\
(0.0001)\end{array}$ & $\begin{array}{c}0.002^{* *} \\
(0.0002)\end{array}$ & $\begin{array}{c}0.003^{* *} \\
(0.0003)\end{array}$ \\
\hline Walkway & $\begin{array}{l}0.007^{* *} \\
(0.002)\end{array}$ & $\begin{array}{l}0.013^{* *} \\
(0.003)\end{array}$ & $\begin{array}{l}0.015^{* *} \\
(0.004)\end{array}$ & $\begin{array}{l}0.014^{* *} \\
(0.005)\end{array}$ \\
\hline Sidewalk & $\begin{array}{l}0.009^{* *} \\
(0.003)\end{array}$ & $\begin{array}{l}0.009^{* *} \\
(0.003)\end{array}$ & $\begin{array}{c}0.008 \\
(0.004)\end{array}$ & $\begin{array}{c}0.010 \\
(0.005)\end{array}$ \\
\hline Lights & $\begin{array}{l}0.0005 \\
(0.002)\end{array}$ & $\begin{array}{c}0.002 \\
(0.003)\end{array}$ & $\begin{array}{c}0.003 \\
(0.004)\end{array}$ & $\begin{array}{c}0.004 \\
(0.005)\end{array}$ \\
\hline Curb & $\begin{array}{c}0.003 \\
(0.003)\end{array}$ & $\begin{array}{c}0.004 \\
(0.003)\end{array}$ & $\begin{array}{c}-0.0002 \\
(0.004)\end{array}$ & $\begin{array}{l}-0.004 \\
(0.006)\end{array}$ \\
\hline Walk Score & $>0$ & $>20$ & $>40$ & $>60$ \\
\hline Census Controls & Y & Y & $\mathrm{Y}$ & $\mathrm{Y}$ \\
\hline MSA Dummies & Y & Y & Y & $\mathrm{Y}$ \\
\hline Observations & 57,750 & 39,640 & 24,240 & 15,681 \\
\hline $\mathrm{R}^{2}$ & 0.751 & 0.703 & 0.663 & 0.640 \\
\hline
\end{tabular}

Note: ${ }^{*}$ and ${ }^{* *}$ indicate significance at the $5 \%$ and $1 \%$ levels, respectively. Census controls, including \% White, Ethnic Heterogeneity, \% No Highschool Diploma, \% Blue Collar Jobs, Median Household Income, and Per Capita Criminal Offenses are significant at the $1 \%$ level. 
divided into houses with and without nearby sidewalks. Note that for houses without access to pedestrian pathways, access to and the variety of nearby establishments, as measured by Walk Score, are no longer predictive of house price. This is understandable, as nearby establishments are inconvenient to walk to when there is no pedestrian infrastructure. When only considering homes with sidewalks, then Walk Score remains positive and significant, with coefficient magnitudes approaching those found in past studies. Additionally, walkways connecting the front of a home to the sidewalk or adjacent street seem to be more valued when those walkways allow for convenient access to pedestrian infrastructure. Lastly, pedestrian safety, as indicated by nearby street lights, leads to increased house sale prices. Therefore, it seems that these safety measures are valuable to homeowners, but only if they possess the necessary complement (i.e. a sidewalk).

As predicted by the monocentric city model, pedestrians may have different preferences depending on where they live relative to the urban center. Again, walkability is valued for more than just access to local amenities like shops and restaurants - many residents value pedestrian infrastructure for pleasure as well. As distance from the city center increases, then one would expect that walkable space becomes less about transportation and more about recreation. Where the urban pedestrian is more likely to use pedestrian infrastructure to walk to work or run errands, the suburban pedestrian is more likely walking the dog for pleasure or jogging for health or recreation. Table 5 addresses the concern that different types of homeowners may have systematically different needs for pedestrian infrastructure dependent upon where they live in relation to the city center. Column 1 is the subsample of all property sales located in suburban space and Column 2 indicates the subsample of property sales in urban space, as indicated by Zillow Neighborhood Boundaries for the state of Ohio. ${ }^{18}$

\footnotetext{
${ }^{18}$ Zillow Neighborhood Boundaries retrieved from: http://www.zillow.com/howto/api/ neighborhoodboundaries.htm
} 
Table 4: Regressions for Log House Price by Access to Nearby Sidewalk

\begin{tabular}{lcc}
\hline \hline & \multicolumn{2}{c}{ Dependent variable: } \\
\cline { 2 - 3 } & No Sidewalk & Sidewalk \\
\hline AC & $0.037^{* *}$ & $0.036^{* *}$ \\
& $(0.004)$ & $(0.006)$ \\
Fireplace & $0.068^{* *}$ & $0.075^{* *}$ \\
Bedrooms & $(0.003)$ & $(0.004)$ \\
& $0.093^{* *}$ & $0.064^{* *}$ \\
Bathrooms & $(0.004)$ & $(0.005)$ \\
& $0.064^{* *}$ & $0.065^{* *}$ \\
Age & $(0.003)$ & $(0.005)$ \\
& $-0.003^{* *}$ & $-0.003^{* *}$ \\
Building SqFt & $(0.0001)$ & $(0.0001)$ \\
& $0.025^{* *}$ & $0.029^{* *}$ \\
Lot Size SqFt & $(0.0003)$ & $(0.0005)$ \\
& $0.001^{* *}$ & $0.001^{* *}$ \\
Deck & $(0.00004)$ & $(0.0001)$ \\
Proximity & $0.058^{* *}$ & $0.069^{* *}$ \\
& $(0.006)$ & $(0.007)$ \\
Walkway & 0.0001 & $0.001^{* *}$ \\
Lights & $(0.0001)$ & $(0.0001)$ \\
& $0.007^{*}$ & $0.017^{* *}$ \\
Curb & $(0.003)$ & $(0.004)$ \\
& -0.002 & $0.010^{*}$ \\
Sidewalk & $(0.003)$ & $(0.004)$ \\
Census Controls & $0.010^{* *}$ & 0.006 \\
MSA Dummies & $(0.003)$ & $(0.005)$ \\
Observations & $\mathrm{N}$ & $\mathrm{Y}$ \\
$\mathrm{R}^{2}$ & $\mathrm{Y}$ & $\mathrm{Y}$ \\
\hline \hline & $\mathrm{Y}$ & 21,250 \\
& 38,035 & 0.727 \\
\hline
\end{tabular}

Note: ${ }^{*}$ and ${ }^{* *}$ indicate significance at the $5 \%$ and $1 \%$ levels, respectively. Census controls, including \% White, Ethnic Heterogeneity, \% No Highschool Diploma, \% Blue Collar Jobs, Median Household Income, and Per Capita Criminal Offenses are significant at the $1 \%$ level. 
Results in Table 5 reflect the likely differences in preferences between urban and suburban residents, wherein it may be observed that while both subsamples enjoy access to local amenities, the magnitude by which proximity to amenities is reflected in property sales is lower for suburban neighborhoods than urban. Proximity to amenities, access to sidewalks, and walkways are valued by both suburban and urban residents, whereas urban residents uniquely value streetlights and suburban residents, curbs. This is not unexpected - if urban residents use pedestrian infrastructure for transportation to work, then they do not necessarily have control over what times they will be walking and may be need to walk at night. Streetlights provide safety to pedestrians in the evenings when visibility is poor. In contrast, if suburban residents are more often using pedestrian infrastructure for recreation, then the choice of when to walk is more open and can be scheduled during the day when streetlights are not necessary. Residents in suburban space may feel safer in general since crime rates are lower, so the addition of street lights in these communities is not valued as much as they would be in cities. Likewise, suburban residents may value curbs because automobiles travel at higher speeds on average outside of the city than within.

Given the apparent importance of access to sidewalks and the differences in preferences of urban and suburban residents for pedestrian infrastructure, I explore subsamples considering both of these attributes as a robustness check in Table 6 . When the samples are broken up, proximity to local amenities still matters for urban residents, but not for suburban residents. Walkways appear to be valued only when they connect homes to the greater network of sidewalks, and the presence of curbs seems to only be valued when there are no sidewalks, likely because residents expect sidewalks and curbs to go hand-in-hand. Lastly, streetlights are not valued by homeowners except for those in urban areas with nearby access to sidewalks. This finding makes intuitive sense, where urban residents are arguably more likely to be required to use pedestrian infrastructure during the evenings for transportation in 
Table 5: Regressions for Log House Price by Type of Neighborhood

\begin{tabular}{|c|c|c|}
\hline & \multicolumn{2}{|c|}{ Dependent variable: } \\
\hline & \multicolumn{2}{|c|}{$\ln ($ Price $)$} \\
\hline & Suburban & Urban \\
\hline $\mathrm{AC}$ & $\begin{array}{c}-0.016^{* *} \\
(0.003)\end{array}$ & $\begin{array}{l}0.073^{* *} \\
(0.006)\end{array}$ \\
\hline Fireplace & $\begin{array}{l}0.060^{* *} \\
(0.003)\end{array}$ & $\begin{array}{l}0.055^{* *} \\
(0.004)\end{array}$ \\
\hline Rooms & $\begin{array}{l}0.060^{* *} \\
(0.003)\end{array}$ & $\begin{array}{l}0.116^{* *} \\
(0.005)\end{array}$ \\
\hline Bathrooms & $\begin{array}{l}0.057^{* *} \\
(0.003)\end{array}$ & $\begin{array}{l}0.080^{* *} \\
(0.005)\end{array}$ \\
\hline Age & $\begin{array}{c}-0.003^{* *} \\
(0.0001)\end{array}$ & $\begin{array}{c}-0.002^{* *} \\
(0.0001)\end{array}$ \\
\hline Building SqFt & $\begin{array}{c}0.0003^{* *} \\
(0.00000)\end{array}$ & $\begin{array}{c}0.0002^{* *} \\
(0.00000)\end{array}$ \\
\hline Lot Size SqFt & $\begin{array}{l}0.00000^{* *} \\
(0.00000)\end{array}$ & $\begin{array}{l}0.00000^{* *} \\
(0.00000)\end{array}$ \\
\hline Deck & $\begin{array}{l}0.054^{* *} \\
(0.005)\end{array}$ & $\begin{array}{l}0.158^{* *} \\
(0.009)\end{array}$ \\
\hline Proximity & $\begin{array}{l}0.0004^{* *} \\
(0.0001)\end{array}$ & $\begin{array}{c}0.002^{* *} \\
(0.0001)\end{array}$ \\
\hline Sidewalk & $\begin{array}{l}0.014^{* *} \\
(0.003)\end{array}$ & $\begin{array}{l}0.010^{*} \\
(0.004)\end{array}$ \\
\hline Walkway & $\begin{array}{l}0.011^{* *} \\
(0.003)\end{array}$ & $\begin{array}{l}0.016^{* *} \\
(0.004)\end{array}$ \\
\hline Lights & $\begin{array}{l}-0.002 \\
(0.003)\end{array}$ & $\begin{array}{l}0.009^{*} \\
(0.004)\end{array}$ \\
\hline Curb & $\begin{array}{l}0.016^{* *} \\
(0.003)\end{array}$ & $\begin{array}{l}-0.003 \\
(0.005)\end{array}$ \\
\hline Urban & $\mathrm{N}$ & Y \\
\hline Census Controls & $\mathrm{Y}$ & Y \\
\hline MSA Dummies & $\mathrm{Y}$ & $\mathrm{Y}$ \\
\hline Observations & 35,538 & 23,747 \\
\hline $\mathrm{R}^{2}$ & 0.734 & 0.686 \\
\hline
\end{tabular}

Note: ${ }^{*}$ and ${ }^{* *}$ indicate significance at the $5 \%$ and $1 \%$ levels, respectively. Census controls, including \% White, Ethnic Heterogeneity, \% No Highschool Diploma, \% Blue Collar Jobs, Median Household Income, and Per Capita Criminal Offenses are significant at the $1 \%$ level. 
spaces where walking for transportation is feasible and convenient. While the results are not identical, Table 6 generally supports evidence suggested by Tables 4 and 5 when considering both access to sidewalks and different preferences of pedestrians.

\subsection{Conclusions and Future Research}

The walkability of a home measures the efficiency, safety, and pleasure of nearby pedestrian transportation. Current measures of walkability that have been utilized in the literature are either easy to obtain, but are lacking in some way, or are prohibitively expensive to collect. To fill this gap in measuring the walkability of a home's neighborhood, I supplement a commonly used measure of walkability, Walk Score, with other indicators relevant to the pedestrian experience, such as access to sidewalks, using public access image data and computer vision classification routines. This study more rigorously measures the impact of walkability on residential property sales prices by estimating a hedonic model of house prices using sales and image data from Ohio.

The results show that houses with greater access to local establishments and adequate pedestrian infrastructure sell for more on average than those that do not. However, when the data is split into homes with and without nearby sidewalks, walkable access to nearby establishments ceases to be valuable to homeowners when no pedestrian paths exist. Without access to pedestrian pathing, nearby establishments are inconvenient and unsafe to walk to and residents should not be expected to value local access to these establishments as much.

In addition to contributions to the analysis of the effect of walkability on property value, the computer vision methods described in this paper can inform research in other fields. In cases where geolocational information is available, such as for real estate, computer vision can provide additional information about the attributes or quality of a location. For instance, computer vision techniques could be used to 
Table 6: Regressions for Log House Price by Access to Sidewalks and Type of Neighborhood

\begin{tabular}{|c|c|c|c|c|}
\hline & \multicolumn{4}{|c|}{ Dependent variable: } \\
\hline & \multicolumn{4}{|c|}{$\ln$ (Price) } \\
\hline & $(1)$ & $(2)$ & $(3)$ & $(4)$ \\
\hline \multirow[t]{2}{*}{$\mathrm{AC}$} & $0.012^{* *}$ & $0.088^{* *}$ & $0.014^{*}$ & $0.072^{* *}$ \\
\hline & $(0.004)$ & $(0.008)$ & $(0.007)$ & $(0.012)$ \\
\hline \multirow[t]{2}{*}{ Fireplace } & $0.057^{* *}$ & $0.078^{* *}$ & $0.075^{* *}$ & $0.066^{* *}$ \\
\hline & $(0.004)$ & $(0.005)$ & $(0.005)$ & $(0.007)$ \\
\hline \multirow[t]{2}{*}{ Rooms } & $0.071^{* *}$ & $0.132^{* *}$ & $0.069^{* *}$ & $0.064^{* *}$ \\
\hline & $(0.004)$ & $(0.006)$ & $(0.006)$ & $(0.009)$ \\
\hline \multirow[t]{2}{*}{ Bathrooms } & $0.046^{* *}$ & $0.085^{* *}$ & $0.057^{* *}$ & $0.064^{* *}$ \\
\hline & $(0.004)$ & $(0.006)$ & $(0.005)$ & $(0.008)$ \\
\hline \multirow[t]{2}{*}{ Age } & $-0.003^{* *}$ & $-0.003^{* *}$ & $-0.003^{* *}$ & $-0.003^{* *}$ \\
\hline & $(0.0001)$ & $(0.0001)$ & $(0.0001)$ & $(0.0002)$ \\
\hline \multirow[t]{2}{*}{ Building SqFt } & $0.0003^{* *}$ & $0.0002^{* *}$ & $0.0003^{* *}$ & $0.0003^{* *}$ \\
\hline & $(0.00000)$ & $(0.00001)$ & $(0.00001)$ & $(0.00001)$ \\
\hline \multirow[t]{2}{*}{ Lot Size SqFt } & $0.00000^{* *}$ & $0.00000^{* *}$ & $0.00000^{* *}$ & $0.00000^{* *}$ \\
\hline & $(0.00000)$ & $(0.00000)$ & $(0.00000)$ & $(0.00000)$ \\
\hline \multirow[t]{2}{*}{ Deck } & $0.036^{* *}$ & $0.097^{* *}$ & $0.046^{* *}$ & $0.113^{* *}$ \\
\hline & $(0.006)$ & $(0.013)$ & $(0.008)$ & $(0.014)$ \\
\hline \multirow[t]{2}{*}{ Proximity } & 0.0002 & $0.001^{* *}$ & 0.0002 & $0.002^{* *}$ \\
\hline & $(0.0001)$ & $(0.0002)$ & $(0.0002)$ & $(0.0002)$ \\
\hline \multirow[t]{2}{*}{ Walkway } & 0.005 & 0.008 & 0.010 & $0.016^{*}$ \\
\hline & $(0.004)$ & $(0.005)$ & $(0.005)$ & $(0.007)$ \\
\hline \multirow[t]{2}{*}{ Lights } & -0.004 & -0.003 & -0.001 & $0.017^{*}$ \\
\hline & $(0.004)$ & $(0.005)$ & $(0.005)$ & $(0.007)$ \\
\hline \multirow[t]{2}{*}{ Curb } & $0.012^{* *}$ & $0.013^{*}$ & 0.001 & -0.004 \\
\hline & $(0.004)$ & $(0.005)$ & $(0.006)$ & $(0.008)$ \\
\hline Urban & $\mathrm{N}$ & $\mathrm{Y}$ & $\mathrm{N}$ & $\mathrm{Y}$ \\
\hline Sidewalk & $\mathrm{N}$ & $\mathrm{N}$ & $\mathrm{Y}$ & $\mathrm{Y}$ \\
\hline Census Controls & $\mathrm{Y}$ & $\mathrm{Y}$ & $\mathrm{Y}$ & $\mathrm{Y}$ \\
\hline MSA Dummies & $\mathrm{Y}$ & $\mathrm{Y}$ & $\mathrm{Y}$ & $\mathrm{Y}$ \\
\hline Observations & 23,773 & 14,262 & 11,765 & 9,485 \\
\hline $\mathrm{R}^{2}$ & 0.745 & 0.713 & 0.747 & 0.696 \\
\hline
\end{tabular}

Note: ${ }^{*}$ and ${ }^{* *}$ indicate significance at the $5 \%$ and $1 \%$ levels, respectively. Census controls, including \% White, Ethnic Heterogeneity, \% No Highschool Diploma, \% Blue Collar Jobs, Median Household Income, and Per Capita Criminal Offenses are significant at the $1 \%$ level. 
analyze photos of the insides of homes for which sales information is available to test whether or not remodeling a home before sale is worth the time and money.

Applications of computer vision are far-reaching and may be useful in fields outside of real estate economics, such as regional development and urban planning. Very fine remote sensing imaging, perhaps to count cars in parking lots across time, could be used to improve development measures as growth of lights at night had in Henderson et al. (2012). Such incredibly fine data would need to be processed, and computer vision is a feasible solution. Creative applications of computer-aided image classification, along with ever-increasing access to image data, has the capacity to yield incredible insight into many economic problems.

A more comprehensive view of walkability needs to be considered by economists and urban planners in future research. While it has, in the past, been difficult to acquire large datasets concerning the quality of pedestrian infrastructure, the advances in and simplicity of executing appropriate computer vision routines, along with the immense and ever-increasing collection of publicly available images, trivializes the acquisition of such data today. By only focusing on the destinations and ignoring the journey, the pedestrian experience is not accounted for and the practical walkability of a space has not been measured.

Future work on this subject will identify other omitted measures of the pedestrian experience, such as the aesthetic properties of pedestrian paths. Because the sample in question only represents a cross-section of home sales in Ohio and a suitable instrumental variable is not immediately obvious, the isolation of a causal effect of pedestrian infrastructure on home sales is difficult. Differences in walking culture between cities and states, or the likelihood with which a household in a given community will use pedestrian infrastructure, might further explain how households value walkability. Recent trends have shown millennials increasingly moving to urban space and forgoing the use of automobiles in favor of walking and public 
transportation. For these reasons, policy makers may consider encouraging the construction of sidewalks and other pedestrian infrastructure. In future studies, samples from other cities and states would be valuable in further studying the impact of walkability on property prices. 


\section{The Value of Aesthetics in Real Estate: An Application of Computer Vision Technologies}

\section{$2.1 \quad$ Introduction}

A family's home is an enormously important part of their lives: they start and end their days at home and spend a disproportionately large time at home compared to elsewhere. The choice of a home is an immense decision, both because of the

time required as well as the expense. People decide to buy homes for a variety of different reasons, from the size and quality of the house, the state of the appliances and utilities, nearness to amenities such as high quality elementary schools, and the privacy and security of the neighborhood. Might people also choose a home based off of its appearance or the appearance of the home's surroundings? This is not an unbelievable notion, as countless magazines, television shows, and online sources are dedicated to the discussion of how to improve a home's "curb appeal," or its exterior aesthetics.

How much does a home's "curb appeal" influence the likelihood of a home being sold, or the price at which the home sells? Real estate economists are ill-equipped to answer questions concerning the appearance of homes in models of real estate sales because specific data concerning visual attributes are rarely reported by real estate assessors. At best, aesthetic characteristics and the state of the home at any given time can be abstracted away from with repeat-sales models, wherein an assumption is made that, due to the durability of housing, characteristics of a home can be considered time invariant between two sales. However, in ignoring the visual characteristics of a home, economists overlook an oftentimes crucial attribute determining the sale of a home, possibly attributing these effects to something else.

By utilizing machine learning and computer vision algorithms, I gather data of characteristics of a home from images of that home and its surroundings. 
Computer vision, in the midst of the big data revolution and the ever-increasing availability of image data, is a state-of-the-art technology that can greatly improve the understanding of processes in real estate markets. Using information gathered from images from a sample of residential real estate sales from Denver and Boulder, Colorado between 2000 and 2014, I improve upon residential home sales model estimation and shed light on the aesthetic properties of a home and its surroundings that most matter in predicting the sales price of a home. Using a standard hedonic specification, I show that relevant data can be gathered on the aethetics of homes and demonstrate the value of some attributes of a home's appearance on a given home's sale price. Lastly, I perform a test on the prediction accuracy of the visual learning algorithm and demonstrate the procedure's robustness to visual noise which may complicate classification of the aesthetic characteristics of interest.

\subsection{Existing Literature}

Curb appeal and other visual amenities of a home are considered massively important to the value of a home and the likelihood that a home sells. The National Association of Realtors reports that $63 \%$ of potential home buyers will visit a home that they enjoyed the appearance of while browsing for homes online. ${ }^{19}$ Certainly, the attributes that potential home buyers see when they browse homes online are overwhelmingly related to a given home's exterior: attributes such as trees, a home's siding, driveways, and access to sidewalks are likely impetus persuading visits from potential buyers. Quality exterior characteristics might also signal the likely quality of interior attributes of a home. Surprisingly, while considered important in practice to realtors, the conventional wisdom of home aesthetics has been little tested in the real estate economics literature.

While rarely applied to real estate markets, the effects of beauty more generally

\footnotetext{
${ }^{19}$ http://www .hgtv . com/design/outdoor-design/landscaping-and-hardscaping/10-curbappeal-tips-from-the-pros-pictures
} 
have been researched extensively in economics. For instance, Mobius and Rosenblat (2006) show that more physically attractive workers in a labor market are more confident, with higher confidence leading to increased wages. Furthermore, the authors find that others consider more physically attractive laborers more able, all else equal. In a later paper, Rosenblat (2008) demonstrates through a dictator game experiment that this beauty premiumn has implications on labor market outcomes. More attractive players, especially if female, received a greater portion of the surplus in cases where the partner can view the picture of the player. Other work, perhaps most notably that done by Hamermesh and Biddle (1993), Biddle and Hamermesh (1998), Hamermesh and Parker (2005), and Andreoni and Petrie (2008), explore the impacts of beauty and gender on labor market outcomes in a myriad of contexts.

As for the impact of beauty in the real estate context, Lansford and Jones (1995) is a rare study considering the aesthetic characteristics of a home on its sale price. The authors use data describing home sales in Travis County, Texas, for which the city of Austin is county seat, to determine the value of lake recreation and aesthetic characteristics on home price. Using a hedonic model, the authors find that lake front homes, proximity to lakes, and whether a home has a scenic view of a lake are all significant and positive predictors of a home's sale price. The authors find that twenty-two percent of a home's price is attributable to these recreational and aesthetic components related to lakes in the sample. This is a high, but not unexpected, price premium for being near a lake as water front property conventionally commands higher prices.

Brown and Pollakowski (1977) explore the amenity effects of water-related open spaces on the value of nearby homes. The authors find that homes in Seattle further from waterfronts sell for less. While this result is expected, the objective of the authors is more interested in determining the optimal amount of open space, in as much as that consumers who most prefer water-related open space are also the owners 
of those properties. The authors test their hypothesis by constructing a land value gradient, and conclude that there is no evidence that water-related open space is suboptimal for the sample.

Research on the amenity effects of aesthetic attributes related to home purchase, such as that described above, are few and far between and typically focus on easily gathered data. Lack of research on the topic is understandable as finding or creating data relevant to home aesthetics is nontrivial for many of the external home attributes that conventional wisdom suggests drive purchase decisions of homes. However, by borrowing tools from the computer science and statistics literatures, economists can now acquire data on a home's aesthetics that were previously very costly to obtain. Computer vision is a technology that, when combined with the increasing availability of image data from sources such as Google Street View and real estate database like Zillow, can classify images of homes and create data regarding visual attributes gathered from images of homes.

While not yet applied to real estate economics to the author's knowledge, computer vision technologies are beginning to be used in economics to gather empirical data that would otherwise not exist. Computer vision as a tool has many applications in supplementing datasets, especially in empirical microeconomics applications like real estate and urban economics for which much image data is available. One recent paper uses computer vision to quantify the appearance of streetscapes from survey data about safety of urban space to train their computer vision algorithm (Naik et al., 2016). The authors show that their created urban safety index is correlated with socio-demographic characteristics. Another recent project uses computer vision techniques to quantify the change in the physical appearance of streetscapes in cities (Naik et al., 2015). Naik et al. (2015) explore whether demographic and economic changes precede, follow, or occur simultaneously with changes in the appearance of a city, finding some empirical support for tipping and filtering theories. 
In the present study, I use computer vision technologies to supplement data on home sales and typically available home attributes (e.g. number of bedrooms, square footage, etc.). The computer vision procedures are used to gather information on a home's aesthetic and visual characteristics. I illustrate in this study that computer vision processes can be used to gather a considerable amount of data regarding a home's exterior. I then demonstrate the attributes of a home's exterior reflected in a home's sale price that are considered valuable to homeowners in the sample.

\subsection{Methods}

\subsubsection{Hedonic Method}

For the empirical tests to follow, hedonic pricing models are used. The hedonic pricing method is centered around the notion that one can express the sale price of a home at a given time by the value of the attributes of which the house is composed, such as number of bedrooms and bathrooms, the square footage of the living space, or the presence of a garage (Rosen, 1974). Additionally, superlocal attributes of the community and neighborhood, such as quality and proximity to elementary schools, racial composition, and disamenities like the presence of noise pollution from airports and railways, are also deemed to contribute to the price of a home at the time of a sale. In a hedonic model, the price of a house might be expressed as in Equation 6:

$$
P=f\left(S_{i}, N_{j}, A_{k}\right)
$$

where $S_{j}, N_{k}$, and $A_{k}$ represent vectors describing the structural, neighborhood, and aesthetic attributes of a home, respectively. From the formulation given in Equation

6 , the implicit price of any given attribute of a home, such as aesthetic attributes, $A_{k}$, can be derived as follows:

$$
\frac{\partial P}{\partial A_{k}}=P_{A k}\left(A_{k}\right)
$$


where the partial derivative describes the change in the sale price of a house that would be required to add one more unit of that aesthetic attribute, $A_{k}$, all else equal. Positive values of the partial derivative indicate amenities, whereby a home's sale price following the addition of one more unit of the amenity will increase, and negative values of the partial derivative indicate disamenities. Properties of a home that might be deemed amenities, the addition of which would lead to increases in the sale price of a home, are attributes such as bedrooms, garages, and access to parks. Disamenities, on the other hand, include noise and air pollution or the perception of high crime in the neighborhood, with per-unit increases of these attributes leading to a sinking house sale price.

A log-linear econometric approximation of the hedonic housing price model from Equation 6, emphasizing the estimation of aesthetic characteristic of the home, is estimated as:

$$
\ln (\text { price })_{i j t}=\beta X_{i j t}+\gamma A_{i}+\alpha_{t}+\theta_{j}+\epsilon_{i j t}
$$

where $\ln$ (price) is the natural logarithm of the price of home $i$ in census tract $j$ at year $t, X$ is a vector of non-visual characteristics of the home, $A$ is a vector of external aesthetic home characteristics, $\alpha_{t}$ and $\theta_{j}$ are time and census tract fixed effects, and $\epsilon_{i j t}$ is the stochastic error term. Hedonic models of this sort have been used to analyze a variety of different topics in real estate economics, including the impact of airport noise pollution on residential home sale prices (Nelson, 2004), access to parks and the threat of crime on property value (Troy and Grove, 2008), and access to and quality of nearby schools (Brasington, 1999). ${ }^{20}$

\footnotetext{
${ }^{20}$ Other examples of recent research exploiting the strengths of the hedonic specification in a real estate context include Pope (2008a), Pope (2008a), Linden and Rockoff (2008), and Caudill et al. (2015)
} 


\subsubsection{Computer Vision Data Collection}

Computer vision describes the methods of teaching computers to obtain, process, and understand images, as well as the interdisciplinary field of research that strives to further improve the process of teaching computers to see information in images and apply these findings to real world problems. The data used in computer vision are images: exceptionally high-dimensional data, typically of real world places, people, and objects, to provide insight into the source or construction of the subject of the image, usually in the form of symbolic or numeric outcomes. As a field, computer vision has been most driven to teach computers to not only see images, but to understand the subject of the image - a seemingly farfetched goal, but one that is both motivating and has proven surprisingly attainable, as continued research and application of the techniques leads to greater insight into how machines can be taught to process images. ${ }^{21}$

Applications of computer vision include everything from reconstruction of images and image restoration, for academic use in history and practical use in forensics, to motion estimation and object detection, as well as the technologies that drive the gesture recognition software in Microsoft's Kinect sensor or detect dangerous road conditions and cracked surfaces for self-driving cars. ${ }^{22}$ In this sense, computer vision as a field collects a considerable agglomeration of researchers from numerous fields from Mathematics and Artificial Intelligence researchers, to Robotics, Physics, and even business, developments in computer vision, and the greater machine learning community as a whole, are being driven from all angles.

\footnotetext{
${ }^{21}$ The most prolific project aimed at teaching machines to understand and express what objects in images are is probably Li Fei-Fei's 2015 TED Talk "How We're Teaching Computers to Understand Pictures." The notion of teaching computers to understand instead of just process information has been one of the more popularly exciting attributes of recent machine learning research. Events like IBM's Watson's appearance on the popular trivia gameshow, Jeopardy, have allowed for recent advances in machine learning to capture the public's attention and imagination.

${ }^{22} \mathrm{http}$ ://www.ibtimes.co.uk/heres-how-self-driving-cars-can-detect-dangerous-roads-using-sound-ai-1532407
} 


\subsubsection{The SVM Learning Algorithm}

A Support Vector Machine (SVM) is a machine learning algorithm with application in classification and regression for solving problems as varied as textual analysis and computer vision. The defining characteristic of a SVM is the existence of an optimal separating hyperplane used for classifying a sample possessing linearly separable patterns. A SVM is a discriminative classifier whichf directly maps inputs to class labels. Given a small subset of training data for which the researcher has already categorized, the SVM can use the information it has gathered from analyzing patterns of the training set to categorize new data points. In analyzing the training set, the SVM algorithm can output the optimal hyperplane that separates categories in the training data while maximizing the margin between the most similar, but categorically different, observations.

Very similar data points of different classes from observations in the training set are known as support vectors. Support vectors are those points in the training set that lie very closely to the decision surface. Understandably, data points which are very similar to each other present the greatest headaches in classification problems. For SVMs, these very similar data points, the support vectors, have the greatest and most direct influence on the optimal location for the hyperplane separating the categories.

A particularly nice property of the SVM is its capability of being able to accurately classify observations in problem sets that are not immediately linearly separable. Through the use of a kernel trick, a mathematical property that allows the user to avoid the specifying a specific mapping function to teach linear learning algorithms to understand nonlinear decision boundaries, a SVM can raise the dimensionality of a sample or map observations into new space in a manner that allows for the observations in the training set to be linearly separable (Schiilkopf, 2001). In this sense, SVMs do not, to a degree, suffer from the curse of dimensionality, whereby 
increasingly greater dimensionality leads to problems with sparsity of data. SVMs manage to sidestep this classic problem in the field by utilizing kernel functions to coerce data into space that allows for a decision surface to classify even the most misbehaved members of a category.

Binary classification with SVM begins with a training data consisting of some $N$ pairs, $\left(x_{1}, y_{1}\right),\left(x_{2}, y_{2}\right), \ldots,\left(x_{N}, y_{N}\right) . x_{i}$ is assumed to belong to the set $\mathbb{R}^{p}$ and $y_{i}$ can take class values -1 and 1 . An optimal separating hyperplane is defined as:

$$
f(x)=x^{T} \beta+\beta_{0}=0
$$

and the classification rule

$$
G(x)=\operatorname{sign}\left[x^{T} \beta+\beta_{0}\right]
$$

is generated from $f(x) .{ }^{23}$ As the goal of SVM is to find a hyperplane that maximizes the margin between the two classes in the training data, an optimization problem expressing this goal can be written as

$$
\max _{\beta, \beta_{0},\|\beta\|=1} M \text { s.t. } y_{i}\left(x_{i}^{T} \beta+\beta_{0}\right) \geq M, \quad i=1, \ldots N
$$

where $M$ is the distance from the decision boundary and the edge of the margin. $2 M$ describes the width of the margin about the hyperplane and will be referred to as the margin. The $\|\beta\|=1$ constraint can be eliminated by rewriting the constraint as

$$
\frac{1}{\|\beta\|} y_{i}\left(x_{i}^{T} \beta+\beta_{0}\right) \geq M
$$

allowing for the optimization problem to be conveniently rewritten as

$$
\min _{\beta, \beta_{0}}\|\beta\| \text { s.t. } \quad y_{i}\left(x_{i}^{T} \beta+\beta_{0}\right) \geq 1, \quad i=1, \ldots, N
$$

\footnotetext{
${ }^{23}$ Notation in this section has been adapted and simplified from that of Friedman et al. (2001).
} 
where $\|\beta\|=\frac{1}{M}$ is an arbitrary assignment that allows for the problem to be expressed as a convex optimization problem, choosing $\beta$ and $\beta_{0}$ to maximize the thickness of the margin.

Supposing now that the classes from the training data in the feature space overlap, the SVM can allow for a solution to still be found that maximizes the margin, $2 M$, by allowing for the overlapping class points to be on the wrong side of the margin via a penalty function. The constraint in the optimization problem can be modified as the follows:

$$
y_{i}\left(x_{i}^{T} \beta+\beta_{0}\right) \geq M\left(1-\xi_{i}\right),
$$

where $\forall_{i}, \quad \xi_{i} \geq 0, \quad \sum_{i=1}^{N} \xi_{i} \leq K$, where $\mathrm{K}$ is some chosen constant, and $\xi_{i}=$ $\left.\xi_{1}, \xi_{2}, \ldots, \xi_{N}\right)$ are the slack variables, used to describe the relative distance from the decision boundary by which a given training observation overlaps the wrong classification region (Smith, 1968; Bennett and Mangasarian, 1992). The power of having written the constraint in this way is that it ensures convexity of the objective function. Each measurement of $x_{i}$ must be positive or equal to 0 , where $x_{i}=0$ indicates a correctly classified observation that does not require a penalty, and the sum of all $x_{i}$ must be bounded below some constant, $K$, which effectively binds the total proportional amount that predictions for the testing data are allowed to fall within the wrong class.

Given the new constraint, the objective function of equation 13 can be rewritten as the following optimization problem:

$$
\min \|\beta\| \text { subject to }\left\{\begin{array}{c}
y_{i}\left(x_{i}^{T} \beta+\beta_{0}\right) \geq 1-\xi_{i} \forall_{i}, \\
\xi_{i} \geq 0, \sum \xi_{i} \leq K
\end{array}\right.
$$

which indicates the principal way in which the SV classifier is defined for cases where there is overlap in classification of the training set. Of particular interest of the 
SV classifier is the way in which those points that are properly classified and sit far away from the margin are not the classifiers that are most shaping the optimal separating hyperplane or dictating the width of the margin. More importantly, it is those observations which either sit very close to or within the margin (support vectors), as well as those observations which are misclassified, that most influence location of the hyperplane and width of the margin. ${ }^{24}$

Practically, it makes sense that observations for which classification is particularly straightforward or noiseless should not provide considerably more information than the last straightforward or noiseless observation. Those observations which are difficult to classify, whether because they are similar in attributes to both classes or the data is subject to considerable noise, end up being the ones that most influence the location and direction of the hyperplane. This is a desirable property of SVM because a training set and algorithm which is astoundingly skilled at sorting observations from two incredibly unlike classes is of trivial application, whereas one that can pinpoint minute differences in two very similar classes can solve very costly and difficult problems.

In solving problems of dimensionality, fitting nonlinear decision boundaries, and allowing for points overlapping the wrong class to inform location of the separating hyperplane and band of the margin, the SVM has advantage over the simpler optimal separating hyperplane technique in many ways. SVM as a tool in the statistical

\footnotetext{
${ }^{24}$ Although the solution to the optimization problem will not be treated in this paper, because SVM is a kernelized learning algorithm, a kernel function must be specified. The (Gaussian) radial basis function kernel (RBF) is an extremely popular kernel function used in a number of learning algorithms, and has become the default for support vector machine classification problems for which information about the feature space is relatively unknown or conceptually complicated. The RBF can be expressed as:

$$
K(x, x \prime)=\exp \left(-\gamma\|x-x\|^{2}\right),
$$

where $\gamma=1 / 2 \sigma^{2}$ for simplicity as $\sigma$, is a free parameter which is commonly taken to equal unity. $\|x-x \prime\|^{2}$ is readily interpretable as the squared Euclidean distance between two given feature vectors. The popularity of this particular kernel likely stems from the adaptability of the RBF to a number of different problems as well as the kernel's interpretable nature as a similarity measure, whereby the value of the RBF kernel is bounded between 0 at the limit and 1 where $x=x^{\prime}$. Solutions to the optimization problem described in equation 15 are described in detail in Friedman et al. (2001)
} 
learning toolbox has earned its place, given its relative accuracy, computational load, practical interpretation, and breadth of applications.

\subsubsection{Computer Vision Calibration}

Once images of homes for the sample are collected, analysis of those images can begin. LibSVM, a library of SVMs in the $\mathrm{C}++$ language, was used for all SVM calibration and implementation (Chang and Lin, 2011). The first step in calibrating an unsupervised learning algorithm is to create a training set. For the rest of this section, I will be using the 'tree' variable as the example. The 'tree' attribute was created to indicate the presence of a large tree in the front yard of a home.

Trees might be desirable for homeowners as they obscure the home (and residents) behind them for privacy reasons. Additionally, trees may provide shade to the house, moderating the temperature of the home by blocking sunlight and reducing power consumption. On the other hand, a large tree in the front yard may affect the consistency of moisture content in the soil, increasing the probability of foundation movement under a house, which can require expensive repairs to a home's structure. Also, invasive tree roots can cause damage to sewage systems and home foundations if not kept under control. Preventative measures, such as root barriers or the removal of invasive tree roots, can be taken, but these measures create an additional cost to maintaining a home with a large tree.

For these reasons, the presence of a large tree in the front yard may be seen as an amenity or disamenity to a prospective homeowner. In teaching the computer to recognize images of homes that have at least one large tree in the frame of the image, a training set was created. The training set contains two collections of images: one which contains images of homes without large trees in the frame, and another that contains images of homes that also have images of large trees in them. An example of images from both classes of the 'tree' training set is provided in Figure 3 for reference. 




Figure 3: Trees: Example of Positive and Negative Classes

The first question in designing a training set after determining a visual characteristic of interest is to choose a training set size, N (Matykiewicz and Pestian, 2012; Figueroa et al., 2012). Increasing the number of observations in a training set can improve the accuracy of the learning algorithm in classifying test observations, but has costs in that the algorithm will take longer to process the test images. Clearly, if accuracy only improves mildly but a larger training set quadruples the time it takes to process the data, then it may not be efficient to include the additional training data. For this reason, an exploratory study was conducted on each home attribute to determine appropriate sample sizes for the training set. The 'tree' data will be used as an example of the calibration process to illustrate how decisions about training set size and the values of parameters for the SVM learning algorithm are made.

Once test images are classified into positives and negatives, then the SVM can be trained. The first plot, Figure 4, indicates the change in mean squared error, averaged in each case of the 10 folds, for increasing sample sizes. As can be seen, the average mean squared error begins very high with only 10 images in each class 
for the training data. This shouldn't be unexpected as the computer simply does not have enough information to determine the patterns within the image data with only 20 total images. As the sample size increases slightly, average mean squared error decreases drastically, until around 60 where the average mean squared error evens out. $^{25}$

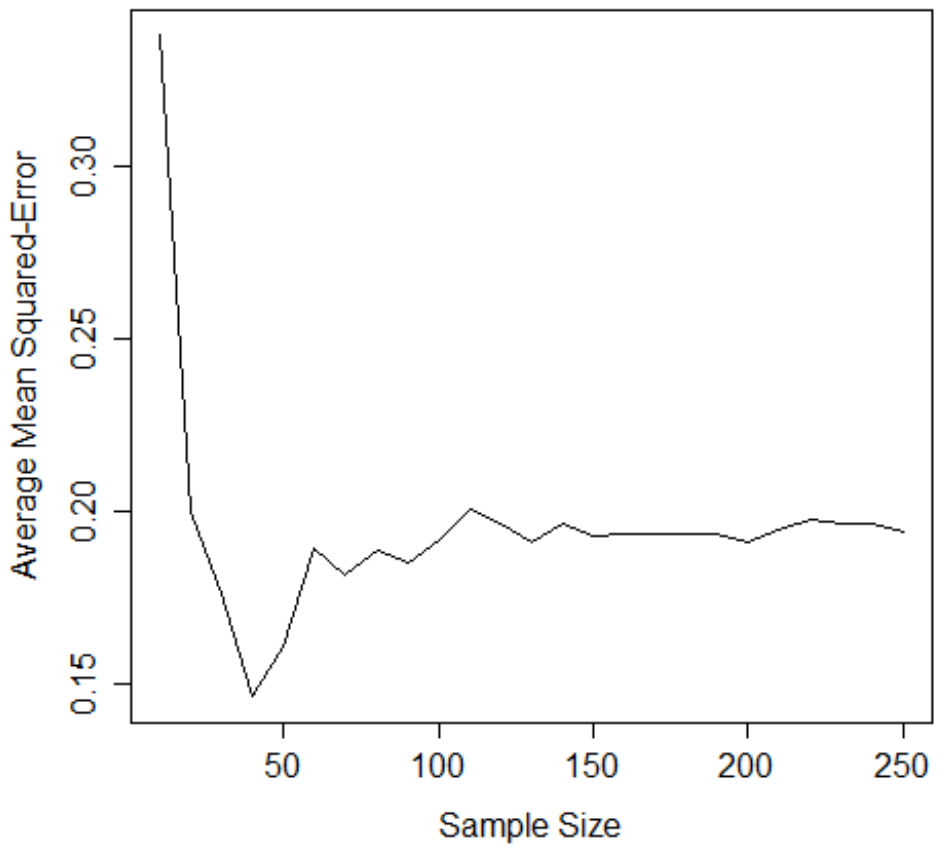

Figure 4: Effect of Training Set Size - Tree Sample - Mean Squared Error

Figures 5 and 6 indicate the change in mean absolute error and mean absolute error squared, respectively, for the 'tree' training data at different values of $N$. Low mean absolute error and mean absolute error squared are desirable, as this indicates a lower classification error. Additionally, mean absolute error and mean absolute

\footnotetext{
${ }^{25}$ Observations between 30 and 50 appear to dip drastically, but this is likely more the result of the randomization of the $K$ - fold cross-validation process in randomly selecting observation groups - each fold in these selections only contains a few observations, so estimation of the accuracy of the cross-validation procedure are more uncertain than for estimation with larger samples, and so more variance is to be expected. A more computationally expensive, but precise, process would be to run estimation of these procedures many times, and then average the resulting mean squared error values across cross-validation procedures within the same sample size, but the time costs of this process compared to the gain in information are very high.
} 
error squared are useful measures that, combined with mean squared error, provide information about the distribution of the errors in the cross-validation procedure. If mean squared error is very close to mean absolute error, then it indicates that the training data makes many, but relatively small, errors in classification. This would indicate many test data that are classified on the wrong side of the optimal separating hyperplane, but at a distance that is not too far away from the hyperplane. On the other end of the spectrum, a mean squared error nearby mean absolute error squared in value indicates that the model makes relatively few, but quite egregious, errors. Such a relationship indicates that there are very few errors, but those errors made are likely deep in the territory of the other class, and maybe even outside of the decision boundary's margin. In the case of the 'tree' data, the error statistics indicate a propensity towards relatively many smaller mistakes rather than few larger errors when misclassifying an image.

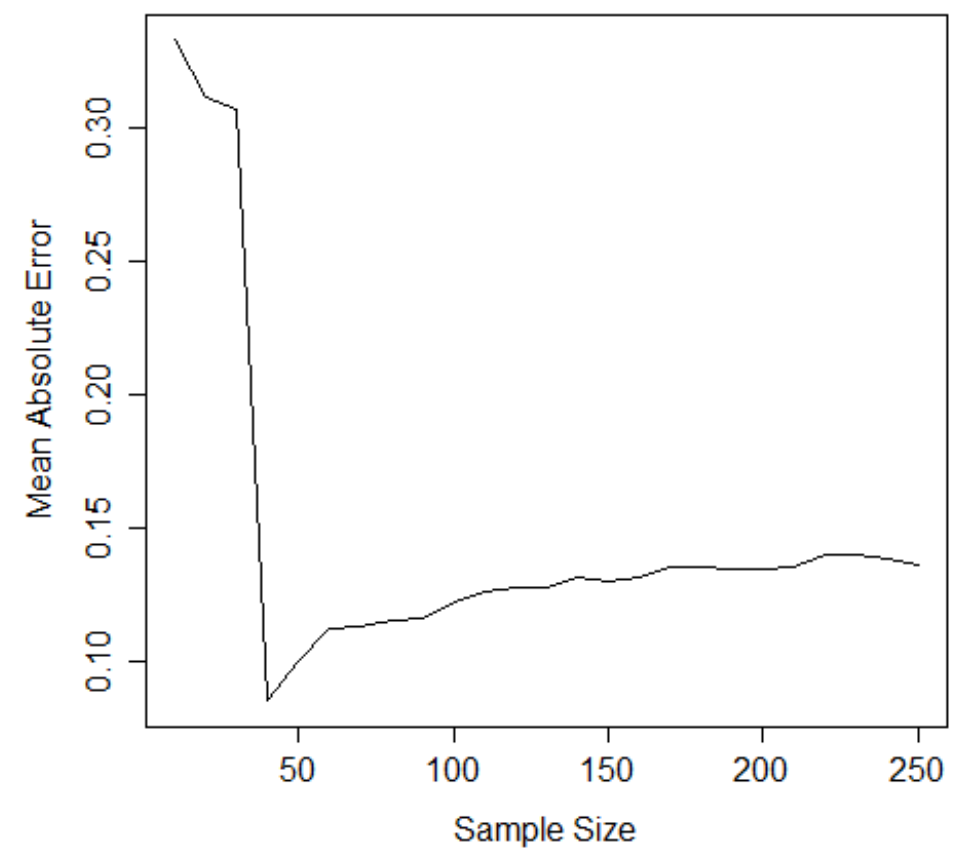

Figure 5: Effect of Training Set Size - Tree Sample - Mean Average Error 


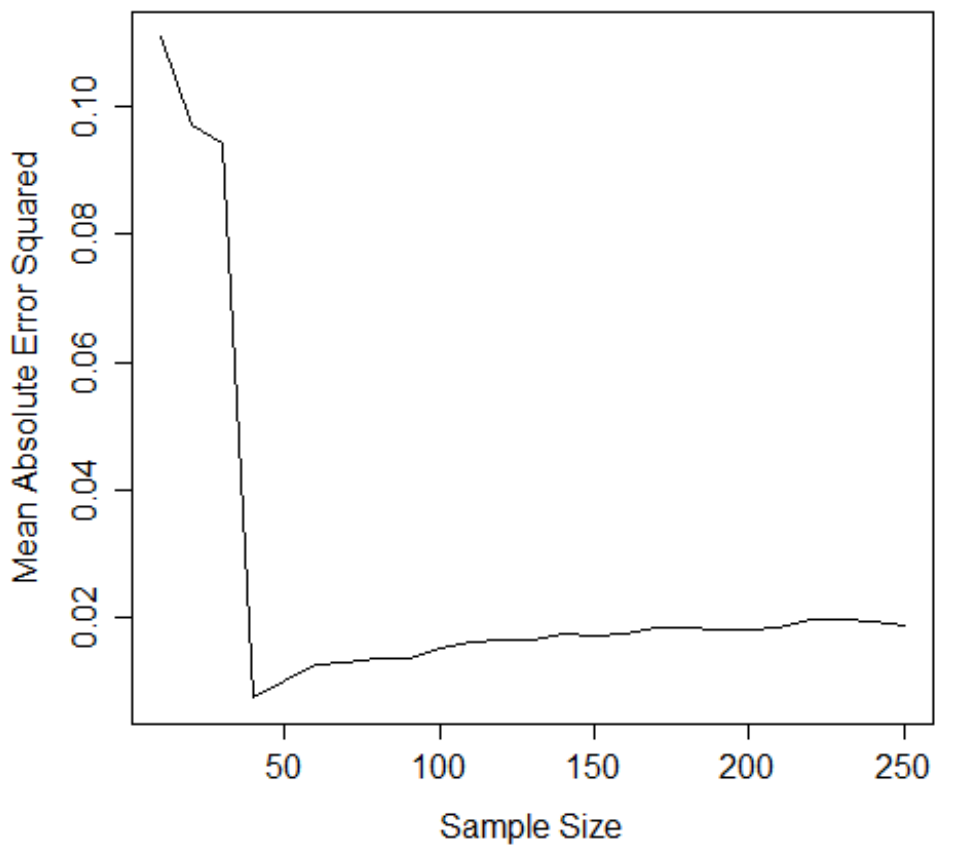

Figure 6: Effect of Training Set Size - Tree Sample - Mean Average Error Squared

Lastly, Figure 7 provides information regarding the value of the squared correlation coefficient. This statistic provides information regarding the fit of the hyperplane to the faux-testing data in the cross-validation procedure. Larger values are desirable as they suggest that the test data are being classified into regions with other like observations. Just as the mean squared error dipped at around 40 observations, and then evened out, the squared correlation coefficient spikes at around the same point, and then sinks and levels out. This large spike is, again, likely the result of few observations in each fold during the cross-validation procedure, where random assignment to the folds encourages unstable results with fewer observations.

The last step before finally letting the algorithm loose on the test data is to decide on appropriate parameter values. A convenient attribute of the SVM learning algorithm is that there are only two important parameters to choose during calibration. The two parameters that are of concern to RBF SVM classification 


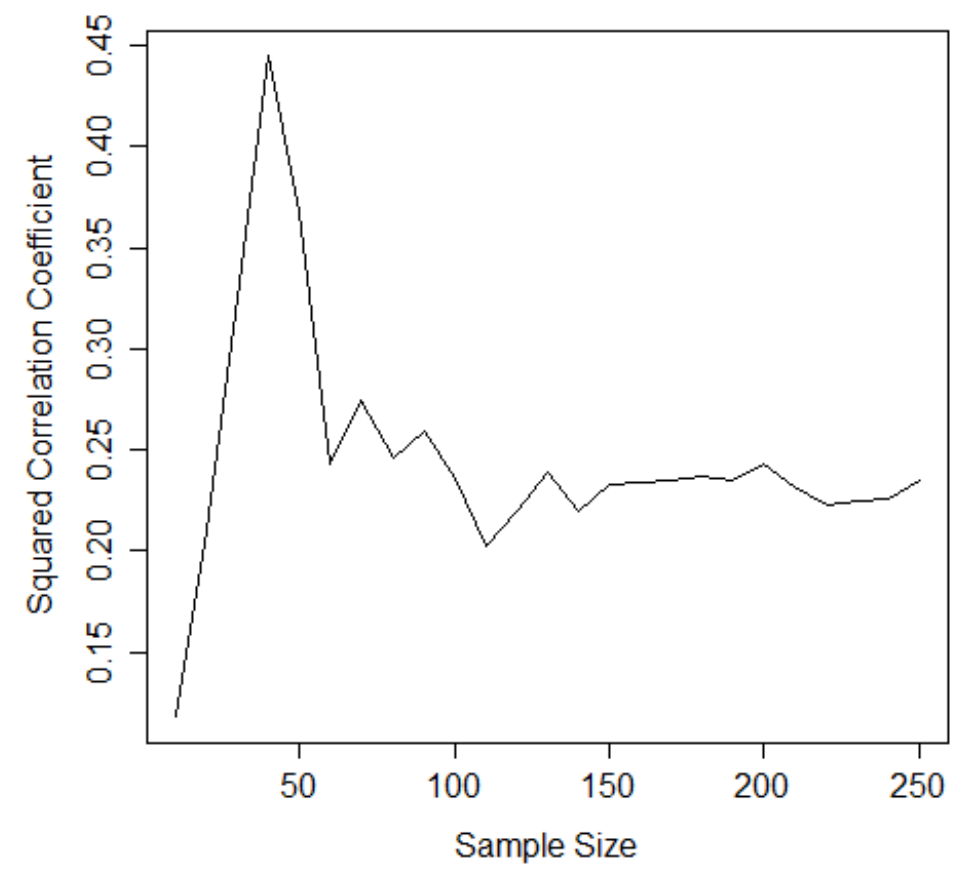

Figure 7: Effect of Training Set Size - Tree Sample - Squared Correlation Coefficient problems are the choices of $\gamma$ and $C . \gamma$ defines how far a single training set observation has influence on the determination of the decision boundary and width of the margin. Low values of $\gamma$ indicate that a faraway point can have influence on the decision boundary, and high values of $\gamma$ indicate that only closer points have influence.

$C$, or cost, is a parameter which signifies a tradeoff between a propensity to misclassify training observations and the relative complexity of the decision surface. For low values of $C$, the decision surface is more smooth, and for higher values of $C$, the SVM tries to classify all training examples correctly by allowing the model to select more support vectors from the training set.

When $\gamma$ is set too small, then the SVM cannot capture and determine the actual shape of the region within which the data are located. However, very large values of $\gamma$ risk overfitting. For $C$, larger costs will make the optimization choose a smaller margin about the decision surface so long as the resulting hyperplane does well in 
categorizing the training sample. For very small values of $C$, the optimizer will allow for larger margins for the separating hyperplane, even if misclassification results. Cost indicates a tradeoff between allowance for misclassification and the possibility of overfitting. In this sense, $C$ is a regularization parameter, controlling these tradeoffs.

While the theory of determining how to set $\gamma$ and $C$ are not well developed, a brute-force, deductive strategy is commonly adopted, by which many SVMs are trained with varying combinations of the two parameters to determine which parameter set most accurately classifies the training set in cross-validation. Figure 8 shows the results of such parameter calibration for the 'tree' training data, at $N=50$, or a training set with 100 total images (50 positive, 50 negative).

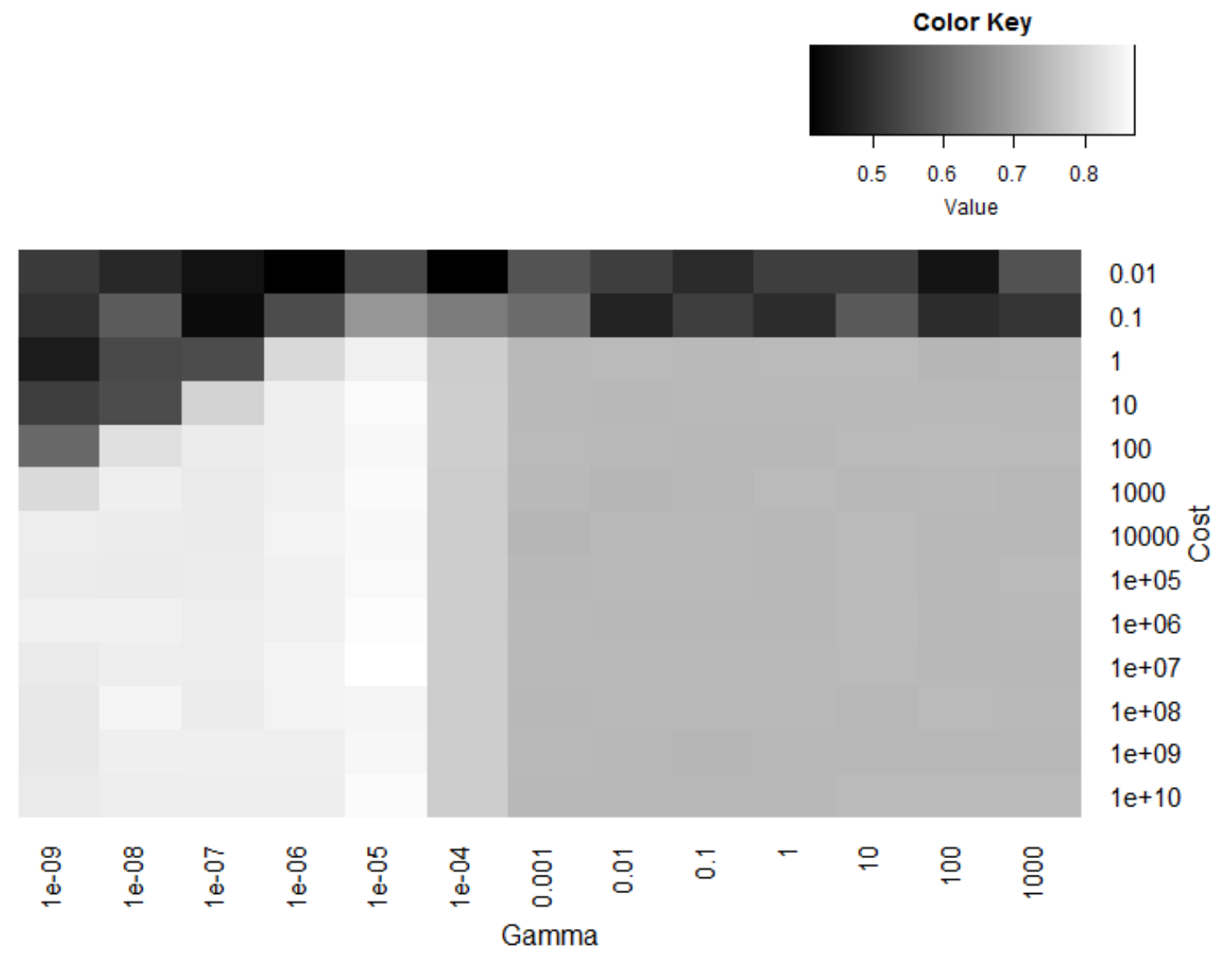

Figure 8: Prediction Accuracy Response to Changes in $\mathrm{C}$ and $\gamma$

The $\gamma$ parameter is denoted along the $\mathrm{x}$-axis, while $C$ is along the $\mathrm{y}$-axis. A 
logarithmic grid is adopted, by which values of $C$ range from 0.01 to $1 e 10$, and values of $\gamma$ from $1 e-09$ to 1000 . When $\gamma$ is very large, the model has a tendency to overfit, and thus makes mistakes in classification of training observations. Very small values of $\gamma$, on the other hand, perform relatively well when the Cost parameter is very large, and quite poorly when the Cost parameter is small. In cases where both parameters are very small, $\gamma$ has a difficult time determining the shapes of the class regions, and the very low cost multiplies these difficulties by allowing for very large margins, further obfuscating the actual partitions separating the classes from the SVM. While large costs seem to generally improve prediction accuracy of the model in classifying training observations, there appear to be a few sweet-spots for which prediction accuracy is minimized.

The column belonging to $\gamma=0.0001$ indicates the optimal value of $\gamma$. As far as cost is concerned in the 'tree' classification problem, the parameter value for $C$ appears to make little difference, so long as there is some minimum value selected that is at or above 1 for reasonable choices of the parameter, $\gamma$. As far as prediction accuracy is concerned, a $\gamma$ of $1 e-05$ and a $C$ of $1 e 07$ are optimal when validating the accuracy of the learning algorithm in classifying observations for the 'tree' classification problem.

The computer vision procedures described in this section are considered best practice for accurate image classification in the field. The procedures described above for the 'trees' variable were applied to the remaining 7 visual characteristics in constructing the data for the subsequent empirical analysis.

\subsection{Data Description}

Data on home sales were retrieved for the counties of Denver and Boulder from their respective county assessor's offices. Altogether, the data span some 15 years, from 2000 to 2014, and encompass 257,399 complete observations, which include non-missing data for attributes of homes shared between the two datasets. Table 
7 displays summary statistics for the housing attributes for which both the Denver and Boulder housing markets share in common. Information that is common to both datasets are statistics about number of bedrooms, number of full and half bathrooms, the size of the basement (whether finished or not) and the area of finished living space, in addition to selling price, the year that the home was built, the date it was sold, and the address of the home.

The sample of home sales and home images used in this study was taken from Denver and Boulder, Colorado. While the geography and topography of the state is incredibly varied, within the counties of Denver and Boulder these attributes are constant. Data from these counties for real estate sales can be retrieved from their respective assessor's offices and contain a surprising amount of information. The primary sample period used in the study is from 2000-2014. Google's Street Cars took pictures of residences in Denver and Boulder primarily between April and November in 2012. While some attributes of a home, such as the material from which the home is made, have likely not changed considerably in 12 years, less permanent aesthetic attributes, such as whether a home's windows possess shutters, may have. It is important to consider the duration of time that has passed between a home sale and the date of the image of the home for certain attributes. Summary statistics for the county of Denver subsample are located in Table 8. Likewise, summary statistics for home sales in Boulder county are in Table 9.

Also listed are characteristics for which the computer was trained to recognize in images of the homes. These attributes take on values of either 0 or 1 , and indicate the presence of said attribute. 'Tree' indicates the presence of a large tree in the front yard. Trees might be desirable for homeowners as they obscure the home (and residents) behind them for privacy reasons. Additionally, trees may provide shade to the house, moderating the temperature of the home by blocking sunlight and reducing power consumption. On the other hand, trees may be considered a disamenity as invasive 
Table 7: Summary Statistics - All Homes

\begin{tabular}{lccccc}
\hline \hline Statistic & $\mathrm{N}$ & Mean & St. Dev. & Min & Max \\
\hline log(price) & 257,429 & 12.564 & 0.706 & 7.003 & 16.020 \\
Total Finished Square Feet & 257,429 & $1,682.711$ & 886.119 & 0 & 44,172 \\
Basement Square Feet & 257,429 & 634.672 & 563.145 & 0 & 7,123 \\
Bed Rooms & 257,429 & 3.089 & 0.997 & 0 & 25 \\
Full Baths & 257,399 & 1.938 & 0.881 & 0 & 31 \\
Half Baths & 257,399 & 0.428 & 0.541 & 0 & 5 \\
Tree & 257,429 & 0.189 & 0.391 & 0 & 1 \\
Walkway & 257,429 & 0.018 & 0.131 & 0 & 1 \\
Patio & 257,429 & 0.012 & 0.110 & 0 & 1 \\
Brick & 257,429 & 0.099 & 0.299 & 0 & 1 \\
Garden & 257,429 & 0.040 & 0.196 & 0 & 1 \\
Pitched Roof & 257,429 & 0.091 & 0.288 & 0 & 1 \\
Shutters & 257,429 & 0.028 & 0.164 & 0 & 1 \\
Symmetry & 257,429 & 0.007 & 0.083 & 0 & 1 \\
\hline
\end{tabular}

tree roots can cause damage to sewage systems and home foundations if not kept under control. Preventative measures, such as root barriers or the removal of invasive tree roots, can be taken, but these measures create an additional cost to maintaining a home with a large tree.

'Walkway' indicates that a home possess a walkway that runs all the way from the door to the street or adjacent sidewalk. A walkway may be valuable to homowners as it connects the home to the pedestrian network. However, walkways require maintenance that homeowners may find to be more costly than the benefits received. 'Patio' indicates if a home possesses a covered, outdoor living space. While some homeowners may value outdoor living spaces for entertaining guests and relaxing, especially in favorable climates, maintenance of a patio pose costs that some homeowners may be uninterested in covering.

'Brick' indicates that a home is made with a material that takes on patterns of brick or stone. Brick outperforms many modern siding materials like vinyl in fire protection and moisture control, and the material is relatively energy efficient due 
to its thermal mass. Because of this, homeowners concerned with energy efficiency and durability might prefer brick or stone siding as opposed to vinyl siding. 'Garden' indicates the presence of either a traditional garden, a rock garden, or shrubbery. While aesthetically pleasing to some, gardens require maintenance that others may not feel is worth the labor.

'Pitched Roof' is an indicator equal to one if a home possesses a pitched roof. Pitched roofs are possibly considered more aesthetically pleasing than flat roofs to homeowners. 'Shutters' describes a home with windows that have shutters on the sides of them. Homes with shutters likely signal that the home is older. Lastly, 'Symmetry' indicates that the home's face possesses symmetry, both in the way that windows and other features are positioned about the door, and in the location of the door relative to the center of the home. Following literature on beauty and labor market outcomes, the 'Symmetry' measure is used to get at a more abstract or subjective measure of beauty of the home and its possible effect on transaction prices

Table 8: Summary Statistics - Denver

\begin{tabular}{lccccc}
\hline \hline Statistic & $\mathrm{N}$ & Mean & St. Dev. & Min & Max \\
\hline $\log ($ price) & 161,604 & 12.444 & 0.755 & 7.003 & 16.020 \\
Total Finished Square Feet & 161,604 & $1,514.812$ & 794.974 & 0 & 15,243 \\
Basement Square Feet & 161,604 & 620.936 & 561.994 & 0 & 7,123 \\
Bed Rooms & 161,604 & 2.780 & 0.831 & 0 & 15 \\
Full Baths & 161,574 & 1.991 & 0.884 & 0 & 9 \\
Half Baths & 161,574 & 0.349 & 0.511 & 0 & 5 \\
Tree & 161,604 & 0.181 & 0.385 & 0 & 1 \\
Walkway & 161,604 & 0.016 & 0.124 & 0 & 1 \\
Patio & 161,604 & 0.006 & 0.079 & 0 & 1 \\
Brick & 161,604 & 0.067 & 0.249 & 0 & 1 \\
Garden & 161,604 & 0.030 & 0.171 & 0 & 1 \\
Pitched Roof & 161,604 & 0.079 & 0.270 & 0 & 1 \\
Shutters & 161,604 & 0.035 & 0.184 & 0 & 1 \\
Symmetry & 161,604 & 0.005 & 0.070 & 0 & 1 \\
\hline
\end{tabular}


Table 9: Summary Statistics - Boulder

\begin{tabular}{lccccc}
\hline \hline Statistic & $\mathrm{N}$ & Mean & St. Dev. & Min & Max \\
\hline log(price) & 95,825 & 12.767 & 0.560 & 8.517 & 15.696 \\
Total Finished Square Feet & 95,825 & $1,965.863$ & 957.028 & 0 & 44,172 \\
Basement Square Feet & 95,825 & 657.837 & 564.329 & 0 & 6,621 \\
Bed Rooms & 95,825 & 3.611 & 1.035 & 0 & 25 \\
Full Baths & 95,825 & 1.848 & 0.870 & 0 & 31 \\
Half Baths & 95,825 & 0.561 & 0.564 & 0 & 4 \\
Tree & 95,825 & 0.203 & 0.402 & 0 & 1 \\
Walkway & 95,825 & 0.021 & 0.142 & 0 & 1 \\
Patio & 95,825 & 0.022 & 0.148 & 0 & 1 \\
Brick & 95,825 & 0.153 & 0.360 & 0 & 1 \\
Garden & 95,825 & 0.057 & 0.231 & 0 & 1 \\
Pitched Roof & 95,825 & 0.111 & 0.314 & 0 & 1 \\
Shutters & 95,825 & 0.016 & 0.124 & 0 & 1 \\
Symmetry & 95,825 & 0.010 & 0.101 & 0 & 1 \\
\hline
\end{tabular}

\subsection{Results}

Results for the given estimation for all residential real estate sales in Boulder and Denver counties are presented in Table 10. Column 1 indicates the baseline model, where no visual characteristics are present in the model. The structural attributes are all informative in predicting the sale price of a home, and with the expected signs. Column 2 examines effects of the visual attributes collected from computer vision analysis of images of homes. The presence of a tree in the front yard of a home is seen as an amenity. This result is intuitive as trees can provide privacy and are aesthetically pleasing to many. Homes appearing to be made of brick or stone sold for more on average while those with window shutters sold for less. Brick and stone homes are valued because the material has been used for centuries as a wall cladding material. Additionally, brick outperforms many modern siding materials like vinyl in fire protection and moisture control, and the material is relatively energy efficient due to its thermal mass. The result for homes with window shutters to sell for less is initially unintuitive. However, it is likely that the presence of window shutters is 
correlated with home age, where older homes are more likely to have window shutters. The remainder of the visual characteristics are not significant for the entire sample.

Next, I consider the possibility that preferences for visual characteristics of homes in Boulder and Denver may differ. The cultures and preferences of citizens of Boulder and Denver are likely quite different, with Boulder being the home of the largest university in the state, and Denver being the more populous and diverse county. Tables 11 and 12 display results for the subsample of home sales in Denver and Boulder, respectively. The results for Denver in Table 11 are very similar to that of the whole sample. The presence of at least one tree in the front yard and brick or stone wall cladding material are both considered amenities. Exterior window shutters are disamenities as they were in Table 10 for the entire sample. The only change in results between Tables 11 and 10 is the newfound disamenity effect from gardens. It is likely that the garden covariate for Denver county is acting as a measure of distance from the city center. Because homes further from the city center will sell for less, all else equal, it is likely that less expensive homes in this sample are the only homes that can afford the space to have gardens.

Table 12 presents results for the subsample from Boulder County only. Contrary to in Denver, the presence of at least one large tree is not particularly effective in explaining home sale prices, while walkways are seen as amenities, even though they were not in Denver County. Trees in Denver County may be considered a luxury and might be more valued. Likewise, access to pedestrian infrastructure via a walkway is probably more often expected in the denser Denver county and therefore may be considered a luxury in Boulder. Patios and brick or stone building materials do not seem to effect home sale prices in Boulder County. While traditional gardens or rock gardens do not appear to be an amenity in Boulder County's housing market as in Denver, homes with pitched roofs and window shutters are both indicative of homes of higher value. Pitched roofs and exterior window shutters are likely seen as aesthetic 
improvements to the appearance of a home from the street, and the significance of these variables signifies that these aesthetic attributes of a home are valued in Boulder County.

Table 10: Effect of Home Characteristics on Sale Price - All Homes

\begin{tabular}{|c|c|c|}
\hline & \multicolumn{2}{|c|}{ Dependent variable: } \\
\hline & \multicolumn{2}{|c|}{$\log ($ price $)$} \\
\hline & (1) & (2) \\
\hline Total Finished Square Feet & $.0002^{* *}(.000)$ & $.0002^{* *}(.000)$ \\
\hline Basement Square Feet & $.0001^{* *}(.000)$ & $.0001^{* *}(.000)$ \\
\hline Bed Rooms & $.029^{* *}(.001)$ & $.029^{* *}(.001)$ \\
\hline Full Baths & $.037^{* *}(.001)$ & $.037^{* *}(.001)$ \\
\hline Half Baths & $.017^{* *}(.002)$ & $.017^{* *}(.002)$ \\
\hline Tree & & $.008^{* *}(.002)$ \\
\hline Walkway & & $.002(.006)$ \\
\hline Patio & & $-.005(.007)$ \\
\hline Brick & & $.009^{* *}(.003)$ \\
\hline Garden & & $-.005(.004)$ \\
\hline Pitched Roof & & $-.0003(.003)$ \\
\hline Shutters & & $-.011^{*}(.005)$ \\
\hline Symmetry & & $-.011(.009)$ \\
\hline Time FE & Yes & Yes \\
\hline Tract FE & Yes & Yes \\
\hline Observations & 257,399 & 257,399 \\
\hline Adjusted $\mathrm{R}^{2}$ & .717 & .717 \\
\hline
\end{tabular}

Lastly, as a robustness check on the capabilities of the computer vision technologies, I consider the effect that large trees might have in deceiving the learning algorithm in classifying the attributes of homes. At times, large trees may obscure considerable portions of the image, possibly rendering it more difficult to properly classify the attributes of homes. While a human can deduce parts of a home through the leaves and limbs of a tree, patterns complicated by limbs in the way of the image of the home may confuse or mislead the learning algorithm. To test whether or not the learning algorithm is robust to this additional noise, the combined regressions of all 
Table 11: Effect of Home Characteristics on Sale Price - Denver

\begin{tabular}{|c|c|c|}
\hline & \multicolumn{2}{|c|}{ Dependent variable: } \\
\hline & \multicolumn{2}{|c|}{$\log ($ price $)$} \\
\hline & $(1)$ & $(2)$ \\
\hline Total Finished Square Feet & $.0002^{* *}(.000)$ & $.0002^{* *}(.000)$ \\
\hline Land Square Feet & $.00001^{* *}(.000)$ & $.00001^{* *}(.000)$ \\
\hline Unfinished Basement Square Feet & $.0001^{* *}(.000)$ & $.0001^{* *}(.000)$ \\
\hline Finished Basement Square Feet & $.00005^{* *}(.000)$ & $.00005^{* *}(.000)$ \\
\hline Bed Rooms & $.029^{* *}(.002)$ & $.029^{* *}(.002)$ \\
\hline Full Baths & $.037^{* *}(.002)$ & $.037^{* *}(.002)$ \\
\hline Half Baths & $.025^{* *}(.003)$ & $.025^{* *}(.003)$ \\
\hline Tree & & $.015^{* *}(.003)$ \\
\hline Walkway & & $-.009(.009)$ \\
\hline Patio & & $-.024(.014)$ \\
\hline Brick & & $.016^{* *}(.005)$ \\
\hline Garden & & $-.015^{*}(.007)$ \\
\hline Pitched Roof & & $-.008(.004)$ \\
\hline Shutters & & $-.013^{*}(.006)$ \\
\hline Symmetry & & $-.016(.016)$ \\
\hline Time FE & Yes & Yes \\
\hline Tract FE & Yes & Yes \\
\hline Observations & 161,558 & 161,558 \\
\hline Adjusted $\mathrm{R}^{2}$ & .698 & .698 \\
\hline
\end{tabular}


Table 12: Effect of Home Characteristics on Sale Price - Boulder

\begin{tabular}{|c|c|c|}
\hline & \multicolumn{2}{|c|}{ Dependent variable: } \\
\hline & \multicolumn{2}{|c|}{$\log ($ price $)$} \\
\hline & $(1)$ & $(2)$ \\
\hline Total Finished Square Feet & $.0002^{* *}(.000)$ & $.0002^{* *}(.000)$ \\
\hline Basement Square Feet & $.0001^{* *}(.000)$ & $.0001^{* *}(.000)$ \\
\hline Car Storage Square Feet & $.0003^{* *}(.000)$ & $.0003^{* *}(.000)$ \\
\hline Bed Rooms & $.019^{* *}(.001)$ & $.019^{* *}(.001)$ \\
\hline Half Baths & $.022^{* *}(.002)$ & $.022^{* *}(.002)$ \\
\hline Three Quarter Baths & $.051^{* *}(.002)$ & $.051^{* *}(.002)$ \\
\hline Full Baths & $.048^{* *}(.002)$ & $.048^{* *}(.002)$ \\
\hline Tree & & $-.002(.003)$ \\
\hline Walkway & & $.018^{* *}(.007)$ \\
\hline Patio & & $-.002(.007)$ \\
\hline Brick & & $.006(.003)$ \\
\hline Garden & & $.002(.004)$ \\
\hline Pitched Roof & & $.010^{* *}(.003)$ \\
\hline Shutters & & $.019 *(.008)$ \\
\hline Symmetry & & $-.015(.010)$ \\
\hline Time FE & Yes & Yes \\
\hline Tract FE & Yes & Yes \\
\hline Observations & 95,825 & 95,825 \\
\hline Adjusted $\mathrm{R}^{2}$ & .743 & .743 \\
\hline
\end{tabular}


attributes are estimated again, once for all observations in the sample, and once more omitting observations for which there are large trees in the front yard of a home. It might be that large trees in the front of a home cause systematic misclassification by the learning algorithm, and behaviors like this may then bias the results of estimation of the hedonic pricing model.

Tables 13, 14, and 15, present the results of the regressions omitting observations of homes that may be obscured by the presence of large trees. Column (1) in these tables are the respective results from Column (2) in Tables 10, 11, and 12 for comparison. Column (2) describes a subsample of specification (1) which excludes homes with trees in the front yards for the purposes of this robustness check. As can be seen from the tables, the signs and relative of magnitudes of the variables concerning the characteristics gathered from the images of homes appear to be robust to the potential complications of noise presented by the presence of large trees in the image.

\subsection{Conclusion}

External attributes of a home are considered by conventional wisdom to be very important to the value of a home and the likelihood of its sale. Despite the perceived importance of a home's appearance on sale price, little empirical research in economics has considered the impact of beauty on home value. This is, however, understandable as data concerning the appearance of a home has been fundamentally difficult to obtain as they are seldom included in real estate databases in any easily quantifiable form. To fill this gap in the data, I supplement typically available data on home sales from Boulder and Denver, Colorado with data gathered from public access image data of a home's exterior using computer vision classification routines. In doing so, this study can arrive closer to an empirical estimation of the value of external home aesthetics than has been done in the literature to this point.

The results of this study confirm conventional wisdom that attributes of the 
Table 13: Effect of Home Characteristics on Sale Price - All Homes - Tree Obstruction

\begin{tabular}{|c|c|c|}
\hline & \multicolumn{2}{|c|}{ Dependent variable: } \\
\hline & \multicolumn{2}{|c|}{$\log ($ price $)$} \\
\hline & $(1)$ & $(2)$ \\
\hline Total Finished Square Feet & $.0002^{* *}(.000)$ & $.0002^{* *}(.000)$ \\
\hline Basement Square Feet & $.0001^{* *}(.000)$ & $.0001^{* *}(.000)$ \\
\hline Bed Rooms & $.029^{* *}(.001)$ & $.028^{* *}(.001)$ \\
\hline Full Baths & $.037^{* *}(.001)$ & $.035^{* *}(.002)$ \\
\hline Half Baths & $.017^{* *}(.002)$ & $.015^{* *}(.002)$ \\
\hline Walkway & $.004(.006)$ & $.006(.008)$ \\
\hline Patio & $-.005(.007)$ & $-.004(.008)$ \\
\hline Brick & $.010^{* *}(.003)$ & $.008^{* *}(.003)$ \\
\hline Garden & $-.005(.004)$ & $-.005(.005)$ \\
\hline Pitched Roof & $-.001(.003)$ & $-.003(.003)$ \\
\hline Shutters & $-.011^{*}(.005)$ & $-.013^{*}(.005)$ \\
\hline Symmetry & $-.012(.009)$ & $-.014(.010)$ \\
\hline Time FE & Yes & Yes \\
\hline Tract FE & Yes & Yes \\
\hline Trees Included? & Yes & No \\
\hline Observations & 257,399 & 208,779 \\
\hline Adjusted $\mathrm{R}^{2}$ & .717 & .711 \\
\hline
\end{tabular}


Table 14: Effect of Home Characteristics on Sale Price - Denver - Tree Obstruction

\begin{tabular}{|c|c|c|}
\hline & \multicolumn{2}{|c|}{ Dependent variable: } \\
\hline & \multicolumn{2}{|c|}{$\log ($ price $)$} \\
\hline & $(1)$ & $(2)$ \\
\hline Total Finished Square Feet & $.0002^{* *}(.000)$ & $.0002^{* *}(.000)$ \\
\hline Land Square Feet & $.0001^{* *}(.000)$ & $.0001^{* *}(.000)$ \\
\hline Unfinished Basement Square Feet & $.0001^{* *}(.000)$ & $.0001^{* *}(.000)$ \\
\hline Finished Basement Square Feet & $.0001^{* *}(.000)$ & $.0001^{* *}(.000)$ \\
\hline Bed Rooms & $.029^{* *}(.002)$ & $.030^{* *}(.002)$ \\
\hline Full Baths & $.037^{* *}(.002)$ & $.035^{* *}(.003)$ \\
\hline Half Baths & $.025^{* *}(.003)$ & $.021^{* *}(.003)$ \\
\hline Walkway & $-.006(.009)$ & $-.007(.012)$ \\
\hline Patio & $-.025(.014)$ & $-.017(.015)$ \\
\hline Brick & $.018^{* *}(.005)$ & $.015^{* *}(.005)$ \\
\hline Garden & $-.014^{*}(.007)$ & $-.013(.008)$ \\
\hline Pitched Roof & $-.009^{*}(.004)$ & $-.011^{* *}(.004)$ \\
\hline Shutters & $-.014^{*}(.006)$ & $-.013^{*}(.006)$ \\
\hline Symmetry & $-.020(.016)$ & $-.020(.017)$ \\
\hline Time FE & Yes & Yes \\
\hline Tract FE & Yes & Yes \\
\hline Trees Included? & Yes & No \\
\hline Observations & 161,558 & 132,352 \\
\hline Adjusted $\mathrm{R}^{2}$ & .698 & .694 \\
\hline
\end{tabular}


Table 15: Effect of Home Characteristics on Sale Price - Boulder - Tree Obstruction

\begin{tabular}{|c|c|c|}
\hline & \multicolumn{2}{|c|}{ Dependent variable: } \\
\hline & \multicolumn{2}{|c|}{$\log ($ price $)$} \\
\hline & $(1)$ & $(2)$ \\
\hline Total Finished Square Feet & $.0002^{* *}(.000)$ & $.0002^{* *}(.000)$ \\
\hline Basement Square Feet & $.0001^{* *}(.000)$ & $.0001^{* *}(.000)$ \\
\hline Car Storage Square Feet & $.0003^{* *}(.000)$ & $.0003^{* *}(.000)$ \\
\hline Bed Rooms & $.019^{* *}(.001)$ & $.015^{* *}(.002)$ \\
\hline Half Baths & $.022^{* *}(.002)$ & $.024^{* *}(.002)$ \\
\hline Three Quarter Baths & $.051^{* *}(.002)$ & $.055^{* *}(.002)$ \\
\hline Full Baths & $.048^{* *}(.002)$ & $.047^{* *}(.002)$ \\
\hline Walkway & $.018^{* *}(.007)$ & $.024^{* *}(.009)$ \\
\hline Patio & $-.002(.007)$ & $.00002(.007)$ \\
\hline Brick & $.005(.003)$ & $.005(.003)$ \\
\hline Garden & $.002(.004)$ & $.0001(.005)$ \\
\hline Pitched Roof & $.010^{* *}(.003)$ & $.008^{*}(.004)$ \\
\hline Shutters & $.019 *(.008)$ & $.021^{* *}(.008)$ \\
\hline Symmetry & $-.014(.010)$ & $-.012(.010)$ \\
\hline Time FE & Yes & Yes \\
\hline Tract FE & Yes & Yes \\
\hline Trees Included? & Yes & No \\
\hline Observations & 95,825 & 76,411 \\
\hline Adjusted $\mathrm{R}^{2}$ & .743 & .734 \\
\hline
\end{tabular}


exterior of a home, some practical and others purely aesthetic, are valued by homeowners and reflected in the sale price of a home. Attributes such as the quality of wall cladding and trees in the front yards of homes are nearly universally reflected positively in a home's sale price. Other attributes such as gardens in Denver and walkways in Boulder provide differential amenity effects in the two counties, suggesting that preferences for external characteristics likely vary depending on the market.

Future research on the subject of external home characteristics might consider a dependent variable describing likelihood of sale instead of sale price. The National Association of Realtors suggestion that most visits to homes by potential buyers are spurred on by the external aesthetics of a home is a testable hypothesis with relevant data. While the value attributed to individual external attributes of homes are modest in this study, it might be that the presence of these valued attributes has large effects on the likelihood of a potential home buyer visiting a home, or of a home being sold.

In addition to confirmation that external home characteristics are reflected in a home's sale price, this study advances the use of computer vision procedures to collect data from images for use in empirical economics applications. These methods combined with recent and growing access to immense image data represent a fruitful new source of data, especially for real estate research. For instance, in addition to publicly available image data from source like Google Street View, images of the insides of homes from real estate databases such as Zillow might be useful to test several hypotheses concerning the aesthetics of a home or the availability of certain amenities inside the home. Applications of computer vision for expanding available data for empirical economics research are far reaching and are likely useful in fields and questions outside of real estate. It is the hope of the author that this study's introduction of these techniques to the discipline improves availability of relevant data and demonstrates the relative ease at which this new information can be gathered. 


\section{Legal Access to Recreational Marijuana as a Local Amenity}

\subsection{Introduction}

In November 2012, regulated cultivation, sale, and use of marijuana for recreation was legalized in Colorado with the enactment of Colorado Amendment 64. On September 16, 2013, Denver's city council passed a municipal ordinance allowing for retail marijuana establishments. By the end of 2013, 136 recreational marijuana retail licenses were issued, 102 of which were in Denver, alone. ${ }^{26}$ While medical marijuana had been approved in Colorado since 2000, Colorado and Washington were trendsetters for being the first states to legalize recreational use of the drug. Shortly after legalization in Colorado and Washington, Alaska and Oregon followed suit in legalizing recreational use and cultivation of marijuana. Most recently, voters in four more states voted for legalized recreational marijuana in the 2016 elections. Legalization of marijuana is a subject that has grown in profile and will likely be the subject of debate and proposed policy for years to come. For this reason, it is important to begin to understand the implications of legalizing recreational use of marijuana.

Legalization of marijuana has its detractors: for one, legalization of a drug could send the signal that drug use is acceptable and healthy, and might further create new consumers of the substance. In addition, as marijuana is popularly thought of as a gateway drug, in as much as its use may lead to the use of other, potentially more dangerous, narcotics, the legalization and increased availability of marijuana could be feared to act as an entrance for more people into the world of more dangerous drug use. Increased access to marijuana is also argued to increase crime rates, especially

\footnotetext{
${ }^{26}$ http: //gazette.com/list-and-map-colorado-issues-136-licenses-forrecreational-marijuana-sales/article/1511511
} 
for driving under the influence charges and thefts related to the drug.

Proponents of marijuana legalization consider prohibition of marijuana to be a restriction on personal freedom. They argue that legalizing the substance will take marijuana out of the hands of the black market and into the regulated discretion of the state, reducing drug related crimes and incarcerations. Lastly, legalization of marijuana would create an additional market for local government to raise tax revenues, perhaps enabling government to provide more public services (Kilmer et al., 2010).

While the moral or ethical foundations of controlled substance legalization is not a focus of the present analysis, such concerns and benefits related to legalization of marijuana may have externalities on local housing markets. If access to legal marijuana is considered a local amenity or disamenity by homeowners, then traditional hedonic models of property transactions should predict resulting local changes to property values. An exploration into whether access to legalized marijuana is an amenity or disamenity being absorbed into the price of housing in Denver is the focus of this study.

We principally test the hypothesis that the establishment of nearby recreational retail marijuana outlets exhibits (dis)amenity effects on residential property value with a difference-in-differences strategy using publicly available data from Denver on residential property sales and establishments of retail marijuana outlets. The difference-in-differences strategy allows us to isolate clear experimental and control groups and observe effects across distance from newly established retail marijuana outlets while controlling for heterogeneity across neighborhoods and time that may affect property values. For one, with data on the establishment periods of retail marijuana outlets, we can create pre- and post-treatment groups with home sales near the locations of commercial sale of recreational marijuana before and after establishment. Second, we can exploit similarities in property sales nearby particular 
marijuana outlets to control for neighborhood characteristics and isolate the effects of the sale of recreational marijuana from those of the outlet's location.

The results of our study show little evidence that recreational retail marijuana outlets exhibit amenity effects for home sale prices. We determine that while a hedonic model unconcerned with the establishment periods of recreational marijuana outlets and subsequent sale of the substance attributes strong disamenity effects for single family homes and amenity effects for condominiums, these effects largely disappear upon treating the specification with the difference-in-differences estimator. We conclude that proximity to commercial space may affect home transaction prices, but that the specific establishment of recreational marijuana outlets has no differential effect. These results coupled with numerous robustness checks suggest that past studies may have conflated amenity effects associated with nearness to marijuana dispensaries with those of proximity to commercial space.

\subsection{Backgrond and Existing Literature}

The state of Colorado officially legalized the sale and recreational use of marijuana in November 2012. While commercial sale of marijuana for medical use had been legal in Colorado since 2000, the passage of Colorado Amendment 64 (along with similar marijuana reform in the state of Washington) marked the first instance in the US of legalization of the substance for personal recreational use and associated commercial cultivation and sale. While passed at the end of 2012, Amendment 64 did not authorize commercial sale until the beginning of 2014. On September 16, 2013, Denver's city council passed a municipal ordinance allowing retail marijuana establishments. By the end of 2013, 102 recreational marijuana licenses were issued in the city of Denver for operations to begin January 1, 2014. ${ }^{27}$

Marijuana legalization is increasingly entering the forefront of discussion on state

\footnotetext{
${ }^{27}$ http: //gazette.com/list-and-map-colorado-issues-136-licenses-forrecreational-marijuana-sales/article/1511511
} 
policy. Succeeding initial legalization in Colorado and Washington, Alaska and Oregon followed suit and legalized sale and cultivation of marijuana for recreational use over the next two years. Recently, four more states (Nevada, Massachusetts, Maine, and California) voted to legalize recreational marijuana during the November 2016 elections. Other states, such as Ohio, recently failed to legalize commercial sale although possession of marijuana has been decriminalized. While most states have not completely legalized sale, cultivation, and possession of marijuana, the conversation is open in many states with regard to decriminalization of possession all the way to complete legalization of use and sale. In addition to newly proposed legislation, such as the most recent in Illinois designed to legalize cannabis products to boost tax revenues and help alleviate the state's budget crisis $^{28}$, legality of recreational use and sale of marijuana is sure to be the subject of debate and state policy propositions for years to follow.

Considerable research has assessed the economic impacts of marijuana legalization on issues concerning health, public budgets, and other outcomes. With regard to wellbeing, a line of research is concerned with the substitutability of marijuana and alcohol consumption. For instance, Anderson et al. (2013) finds evidence that the legalization of medical marijuana reduces traffic fatalities due to the substitutability of the two drugs. With some exception ${ }^{29}$, the substitutability of marijuana and alcohol is motivated in a variety of health economics research papers, with associated policy implications often focused on the unintended consequences of increasing alcohol consumption with more restrictive marijuana regulation (Crost and Guerrero, 2012; DiNardo and Lemieux, 2001). Related research has also considered the effects of marijuana legalization on suicide rates (Anderson et al., 2014), education and labor market success (Ours and Williams, 2015), and tax revenues (Caputo and Ostrom,

\footnotetext{
${ }^{28}$ http://wgntv. com/2017/03/23/illinois-lawmaker-proposes-legalizing-marijuanasame-as-alcohol/

${ }^{29}$ Pacula (1998), for instance, finds evidence that alcohol and marijuana are economic complements.
} 
1994) amongst other topics. Little research, however, has considered the effects of marijuana and marijuana legalization on home transaction prices.

Much research has considered the effects of nearby amenities and disamenities on housing transaction prices. Linden and Rockoff (2008) use transactions level data and information from sex registrations to estimate the value of the disamenity associated with living nearby convicted criminals. Other examples of research considering the effects of amenities on property value include work considering the effects of power plants (Davis, 2011), brownfields (Linn, 2013), airport noise pollution (Espey and Lopez, 2000), strip clubs (Brooks et al., 2015), and flood zones (Pope, 2008b).

While little published research in economics has considered the effects of the legalization of previously illicit drugs on home sale prices, a wave of research is being developed simultaneously to investigate the effects of marijuana legalization on home transaction prices, especially in Colorado. Cheng et al. (2016) consider the effects of recent legalization of marijuana on municipal-level home prices in an effort to contribute to the cost-benefit analysis of marijuana legalization. By taking advantage of variation in the adoption periods of retail marijuana laws across municipalities, the authors find some evidence suggesting home price increases in municipalities upon relaxation of retail marijuana prohibitions. The authors chalk up this effect to increases in housing demand due to the sudden availability of recreational marijuana without associated expansions in local housing supply.

Another study by Conklin et al. (2016) specifically considers the effects of medical-retail marijuana outlet conversions on proximal home prices. The authors treat the sudden shift of many medical marijuana outlets to recreational stores as an exogenous change with which to create a treatment effect for a difference-in-differences identification strategy. The authors find evidence of a $9 \%$ increase in property prices for single family homes within 0.1 miles from a retail conversion compared to those homes further away. The quantity and variety on the topic of real estate and 
marijuana legalization, as well as the effects of relaxed regulation on issues ranging from health to public finance, is indicative of the interest of academics on the subject and reflective of the public's curiosity over the potential cost and benefits of this highly politicized issue.

The biggest concern for analyis of how the establishment of recreational marijuana outlets may affect home prices has to do with the endogeneity concern between location decisions for these new outlets and associated economic outcomes. For instance: "Does the establishment of marijuana outlets decrease same-neighborhood home values, or are marijuana outlets systematically locating in space with low home value?" These concerns are echoed most predominantly in Boggess et al. (2014) for poverty rates and racial composition. Boggess et al. (2014) find no evidence that marijuana dispensaries increase poverty or change racial composition, but instead find that marijuana centers tend to locate in spaces with more retail employment and greater crime rates in Denver.

Such findings go against the priors of many who believe that the establishment of marijuana outlets are problematic for the local community, and it is crucial for both academics and policy makers to consider the possibility that negative economic outcomes associated with legalized marijuana may simply have to do with the types of commercial spaces these outlets choose. To acknowledge this possible endogeneity problem, we employ a difference-in-differences specification. In exploiting variation across both time and space, we separate the effects of marijuana outlets openings on transaction prices from the location decisions of those outlets. Additionally, we perform a counterfactual experiment as a robustness check and demonstrate that the separation of the marijuana outlets and the space they inhabit in Denver is crucial to correctly estimating the effects of recreational marijuana outlet establishments on local home prices. 


\subsection{Empirical Analysis}

\subsubsection{Data Description}

Analysis of the effect of establishment and proximity of retail and medical marijuana outlets on home value is reliant on data describing the locations and attributes of residential sales in the county of Denver, property sales, and the locations and opening quarter of retail and medical marijuana outlets in the county.

Property transaction data for Denver, Colorado used in this study come from the City and County of Denver Assessment Division. ${ }^{30}$ Observed transactions are restricted to begin in January 1, 2013 until January 1, 2016. During this period, there are 27,965 recorded single family home transactions and 10,128 condomium sales. To eliminate outliers, the data is further restricted to include only sales in excess of $\$ 1,000$ and not exceeding $\$ 10,000,000$. Additionally, only warranty deeds, deeds assuring that the owner has clear title to the property, were kept. Lastly, we Winsorize the property transaction data by absolute residual in order to remove outliers. This leaves 20,143 total sales, 13,457 of which are single family homes and 6,686 are condominiums. Tables 16 and 17 provide summary statistics of the property sales for single family homes and condominiums over the sample period in Denver County.

Data about recreational marijuana dispensaries and the receipt of relevant operational licenses was retrieved from the Colorado Department of Revenue, Enforcement Division's list of retail marijuana facilities. ${ }^{31}$ Because we are interested in how consumer access to recently legalized marijuana affects transaction prices, we consider both recreational and medical marijuana retail outlets. As of March 1, 2017, there are 473 licensed retail marijuana stores and 523 medical marijuana centers in Colorado, a large portion of which are within Denver city limits. ${ }^{32}$

\footnotetext{
${ }^{30}$ https://www. denvergov.org/content/denvergov/en/assessors-office.html

${ }^{31}$ https://www. colorado.gov/pacific/enforcement/med-licensed-facilities

${ }^{32}$ https://www. colorado.gov/pacific/enforcement/licensees-marijuana-enforcement-
} 
When available, licensed retail marijuana store opening dates and addresses were retrieved from the Colorado Secretary of State Business Database, and deduced from relevant web searches and phone calls when the information from the business database was questionable or unavailable. ${ }^{33}$ Retrieved addresses were transformed into geocoordinate data for use in calculating distances for the following analyses. Maps of the distribution of recreational marijuana dispensaries (in black), as well as single family homes (pink) and condominiums (blue), are presented in Figure 9.

Lastly, as a means of controlling for location choices for marijuana outlets, we collect data on the locations and time-of-licensing for liquor outlets across Denver from the Colorado Department of Revenue, Enforcement Division. An argument can be made that if (dis)amenity effects are found on property sale prices from nearness to retail marijuana outlets, the result might be driven by location choices of retail marijuana outlets and not by the operation of these outlets. We consider, for instance, that new marijuana retail outlets may systematically locate in commercial space that is already inhabited by other similar outlets, such as liquor stores, which may be the cause of nearby lower property prices. Additionally, because marijuana outlets locate in commercial space, amenity effects related to proximity to marijuana outlets may simply be attributable to nearness to commercial space. In controlling for the location decisions of outlets, we hope to tease out the effects that marijuana outlets have on property prices separately from the effects of space inhabited by marijuana outlets.

\subsubsection{Methods}

Rosen (1974) posited that a residential property can be thought of as composite good, the price of which can be described as a function of the characteristics of the property, including the characteristics of the house and its surroundings. In this

division

${ }^{33}$ https://www.sos.state.co.us/biz/BusinessEntityCriteriaExt.do 
Table 16: Summary Statistics - Single Family Homes

\begin{tabular}{lcccc}
\hline \hline Statistic & Mean & St. Dev. & Min & Max \\
\hline Sale Price & $410,078.200$ & $257,489.900$ & 46,200 & $2,000,000$ \\
Log Sale Price & 12.773 & 0.536 & 10.741 & 14.509 \\
Land Area & $6,891.727$ & $2,587.891$ & 1,000 & 85,600 \\
Above Ground Area & $1,445.673$ & 733.111 & 316 & 7,624 \\
Basement Area & 698.113 & 552.287 & 0 & 3,358 \\
Stories & 1.229 & 0.421 & 1.000 & 3.000 \\
Bed Rooms & 2.704 & 0.751 & 0 & 5 \\
Full Baths & 2.000 & 0.870 & 0 & 7 \\
Half Baths & 0.292 & 0.488 & 0 & 3 \\
Age & 57.836 & 25.342 & 0 & 100 \\
\hline
\end{tabular}

Table 17: Summary Statistics - Condominiums

\begin{tabular}{lcccc}
\hline \hline Statistic & Mean & St. Dev. & Min & Max \\
\hline Sale Price & $246,908.600$ & $182,477.800$ & 26,000 & $1,990,000$ \\
Log Sale Price & 12.208 & 0.636 & 10.166 & 14.504 \\
Land Area & $1,521.145$ & $2,918.089$ & 46 & 214,000 \\
Above Ground Area & $1,072.115$ & 409.721 & 288 & 4,495 \\
Basement Area & 61.717 & 244.187 & 0 & 2,756 \\
Story & 1.199 & 0.420 & 1 & 4 \\
Bed Rooms & 1.702 & 0.665 & 0 & 4 \\
Full Baths & 1.522 & 0.565 & 1 & 5 \\
Half Baths & 0.187 & 0.397 & 0 & 2 \\
Age & 34.941 & 20.082 & 1 & 100 \\
\hline
\end{tabular}




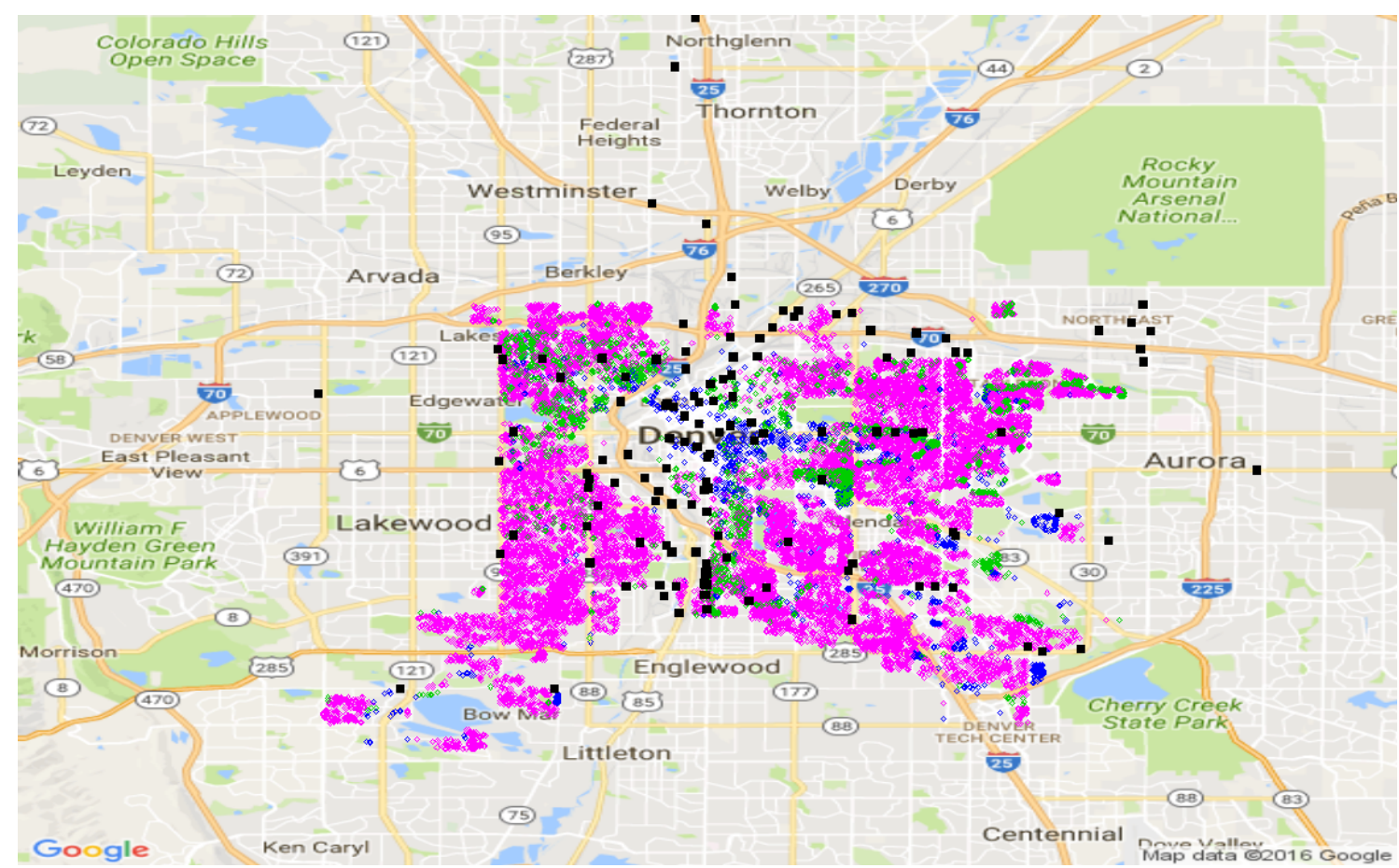

Figure 9: Denver Retail Marijuana Stores and Residential Property Sales

sense, the sale price of a residential property reflects the sum of the implicit prices of each part of the composite good. Hedonic models of this sort have been used to analyze many topics in real estate economics, including the impact of airport noise pollution on residential home sale prices (Nelson, 2004; Pope, 2008a), access to parks and schools (Troy and Grove, 2008; Brasington, 2009), and neighborhood safety (Linden and Rockoff, 2008; Pope, 2008c; Caudill et al., 2015). Consequently, it is not unreasonable to assume that access to marijuana outlets may provide amenity and/or disamenity effects reflected in a home's sale price.

The location choice of a given retail marijuana outlet is crucial. The expected revenues of a dispensary may be reliant upon the likely customer base or the nature of nearby establishments. Marijuana dispensaries may choose to locate within space already inhabited by similar establishments. For one, many recreational dispensaries that emerged following the legalization of the sale of recreational marijuana were previously (or are still operated as) medical marijuana retail outlets. Expanding 
operations to also include the sale of the substance for recreation is a relatively costless business development given that the costs associated with buying the space and establishing a storefront have already been spent, and there are likely economies of scale in applying for licensing for recreational sale given experience that medical outlets have in applying for medical sale.

Marijuana dispensaries may locate in space occupied by similar establishments, such as liquor stores. Just as with outlets selling other regulated substances, homeowners may perceive marijuana dispensaries as centers for crime and urban decay. For this reason, it becomes crucial to separate the effects that a given dispensary's location has on property values from the direct effect of the dispensary on residential property values. Furthermore, nearness to commercial space, regardless of use, may be seen as a disamenity to homeowners. Separating the effects of a retail marijuana outlet's location choice from the amenity effects outlet itself is critical so as not to misattribute the effects of commercial space more generally on transaction prices to dispensaries.

Should the effects of a dispensary and those of the dispensary's surroundings not be disentangled, then variation in the sale price of a residential property may falsely appear to reflect an aversion to living near the space occupied by a marijuana dispensary instead of an aversion to the dispensary itself. For this reason, we examine variation in property values before and after the establishment of a new marijuana dispensary.

From the residuals from a simple hedonic model, we calculate price gradients across distance: one for home sales 12 months before the opening of a marijuana dispensary and one for homes sales 12 months after opening. If the location of a home is considered a disamenity before a recreational marijuana dispensary opened for business, then the price gradient before the marijuana outlet opened should be upward sloping. Likewise, if marijuana dispensaries are disamenities, then the price 
gradient after the opening of the outlet should be decreasing with distance. The price gradients are presented in Figures 10 and 11 for homes and condominiums, respectively.

For single family homes in Figure 10, prices are lowest nearest to locations occupied or soon-to-be-occupied by marijuana dispensaries and appear to flatten out by about a quarter of a mile's distance. However, it appears as if the location on its own may be a disamenity, possibly further exacerbated by the opening of both medical and recreational marijuana retail outlets. This evidence suggests that a simple hedonic model may misattribute some of the effects of nearby disamenities not associated with marijuana dispensaries. For condominiums, the story is less striking. The price gradient for 12 months before and 12 months after both are quite flat for recreational marijuana outlets, suggesting that neither the spaces inhabited by marijuana dispensaries, nor the dispensaries themselves, are likely affecting property values nearby.

In both Figures 10 and 11, gradients tend to move together and flatten out after 0.1 miles from the location of a dispensary, offering evidence that the location of marijuana dispensaries or the spaces they typically locate are having little effect on property prices beyond this range. Given that this is the case, property sales occuring just further away than a tenth of a mile can serve as a statistical control group for estimating the effects of the opening and location of marijuana dispensaries on residential property value.

This study tests for changes in the log price of real estate assets caused by proximity to retail marijuana dispensaries following the legalization of recreational marijuana in November 2012 and subsequent marijuana establishments. We focus on residential real estate properties located within specified distances from marijuana dispensaries. We estimate two types of models: a simple cross-sectional specification and a difference-in-differences specification. The former, while likely not indicative of 


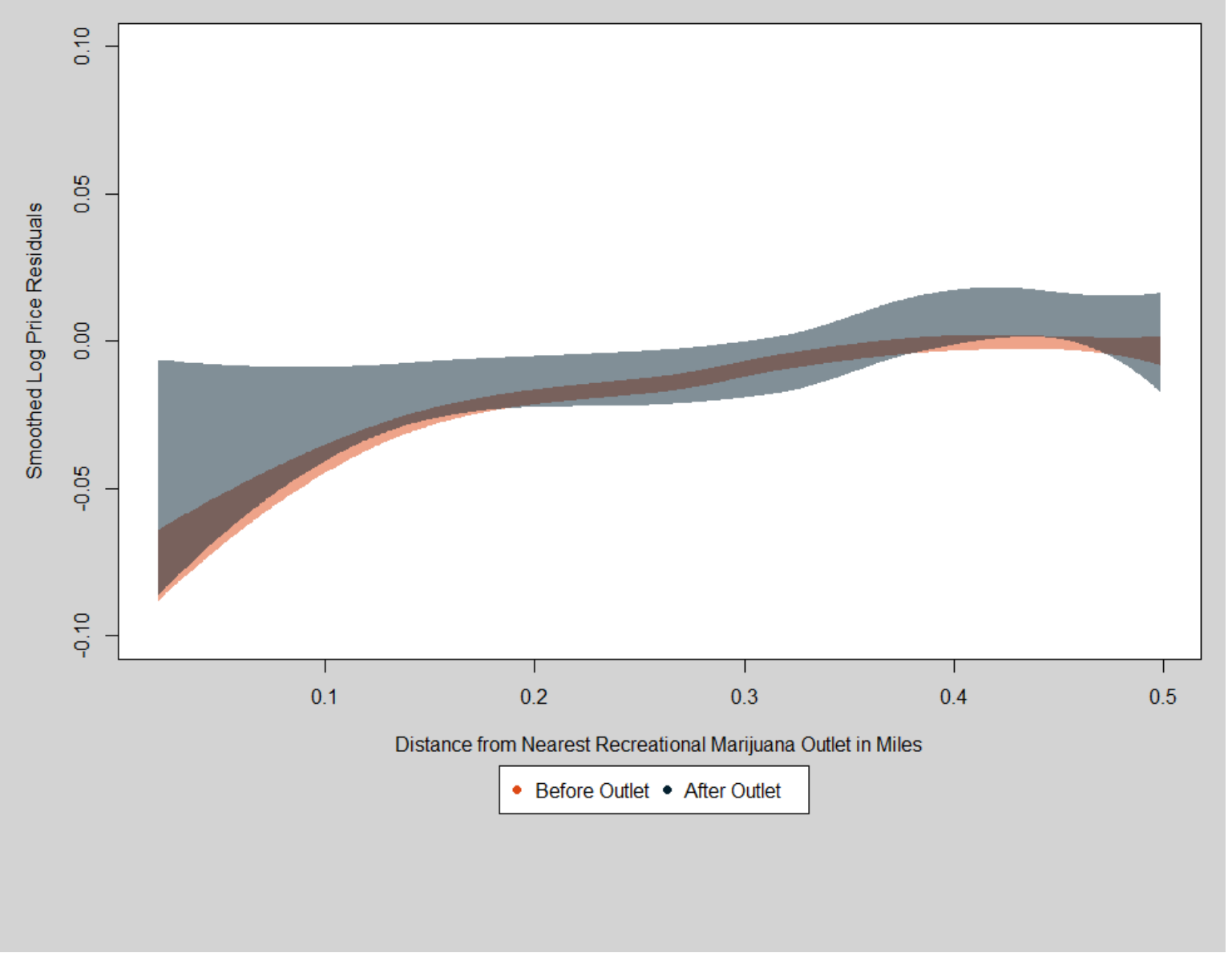

Figure 10: Price Residual Gradients for Single Family Homes 


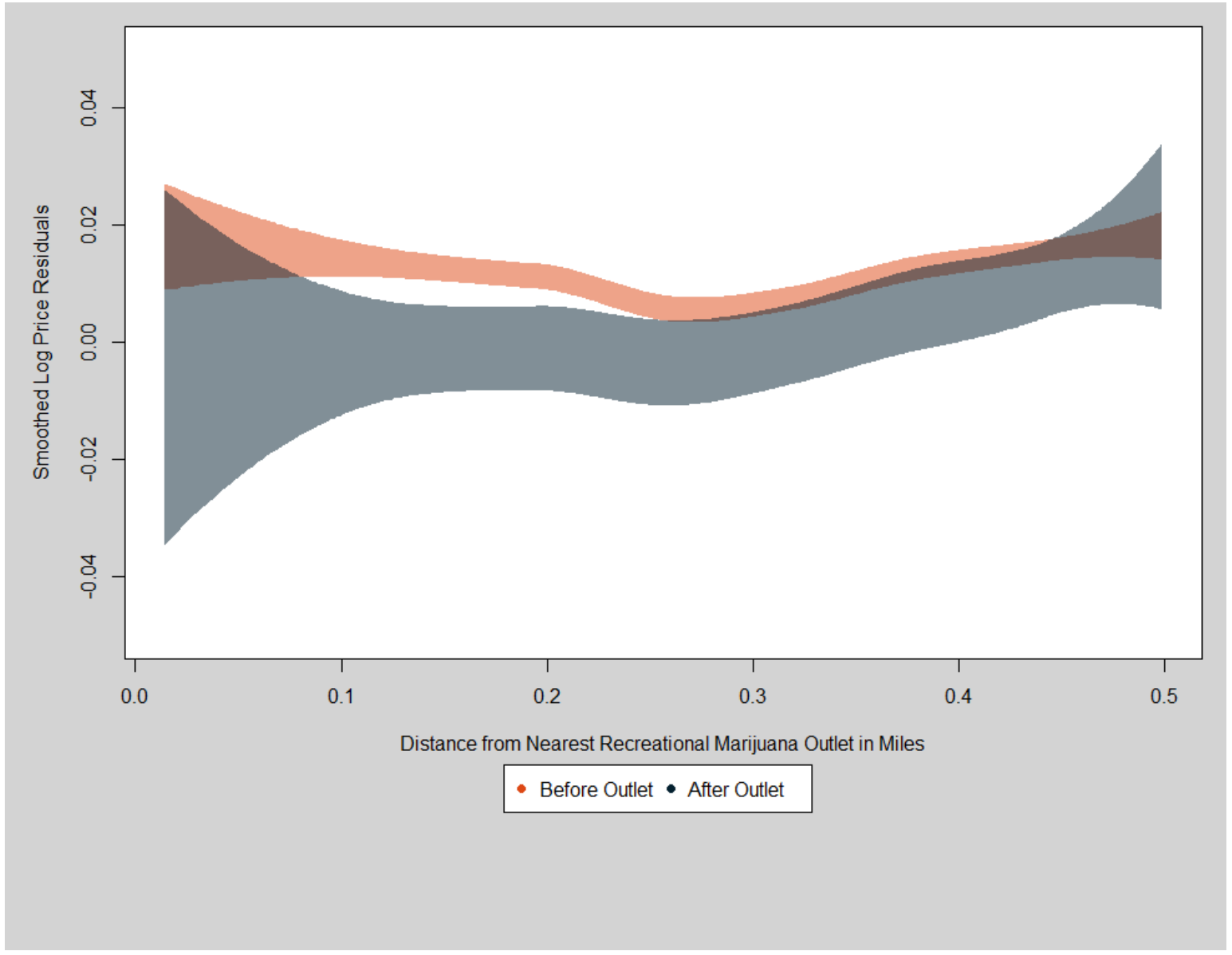

Figure 11: Price Residual Gradients for Condominiums 
the processes underlying the effect of marijuana outlets on property price, is included to consider pre-existing differences in properties and spaces around them both for properties located within 0.1 miles from an outlet and those between 0.1 and 0.25 miles from an outlet.

The distances chosen were informed by the exercise above, wherein we calculated and graphed the price gradients for recreational and medical marijuana outlets and single family homes and condominiums across distance. Given evidence that price gradients before and after the opening of a dispensary tend to track each other and flatten out after a tenth of a mile, we use this distance as a cutoff in determining our experiment and control groups. We exploit the similarity of the properties to then use a difference-in-differences model, wherein residential property sold between 0.1 and 0.25 miles from a marijuana outlet are used as controls for properties sold within a tenth of a mile from the location of a dispensary.

The principal hedonic specification we employ is as follows:

$$
\log (P)=\alpha+\beta X+\gamma_{1} D_{0.1}+\gamma_{2} D_{0.25}+\left(\gamma_{3} D_{0.1}+\gamma_{4} D_{0.25}\right) * \text { Post }+\epsilon
$$

where $\log (P)$ is the $\log$ of the sale price of the house, which is a function of $\alpha$, a census tract-year fixed effect, $X$, the observed property characteristics, $D_{0.1}$, an indicator variable equal to one if a given property sale occured within 0.1 mile from the location of a marijuana outlet, $D_{0.25}$, an indicator equal to one if a given property sale occured between 0.1 and 0.25 miles from the location of a dispensary, and Post, an indicator equal to one if the given property sale took place after the establishment of a marijuana outlet. 


\subsection{Estimation Results}

\subsubsection{The Impact of the Establishment of Recreational Marijuana Outlets}

As a baseline, we begin by presenting estimates of a simple cross-sectional estimation of the effect of the location of recreational marijuana establishments on home price in column (1) of Tables 18 and 19. Tables 18 and 19 represent estimates for single family homes and condominiums, respectively, and constitute the primary evidence of the empirical study. For single family homes in column (1), we find that recreational marijuana dispensaries appear to be a disamenity reflected by residential property values. The story is similar for condominiums in Table 19, wherein condominiums located within a tenth of a mile sell for about $4 \%$ less on average; however, unlike for single family homes, we do not find an effect of the location of recreational marijuana dispensaries on condominium value between 0.1 and 0.25 miles from a dispensary. In both cases, should proximity to a recreational dispensary be a disamenity, the effect dissipates in magnitude with space.

The estimated effect of the opening of a recreational marijuana dispensary is $\gamma_{3}$ from equation 17. Our estimation strategy relies on homes within a tenth of a mile to be similar to homes located within a quarter mile from a recreational marijuana dispensary. Given that these homes are similar, after controlling for differences in property characteristics and the locations and periods for which marijuana establishments opened for business, $\gamma_{3}$ describes the effect of the opening of a marijuana dispensary on residential property prices.

While column (1) in Tables 18 and 19 indicates some evidence that recreational marijuana dispensaries constitute a disamenity for residential property sales, the results of this equation are subject to concerns that they reflect a homeowner's aversion to living nearby the location of a given dispensary, and not necessarily the dispensary itself. Should the $\gamma_{3}$ parameter estimate be significant in equation 
17, then one may more safely conclude that recreational marijuana dispensaries are disamenities. In column (2) of both Tables 18 and 19, we estimate an equation of the form given by equation 17. For both single family homes and condominiums, $\gamma_{3}$, as represented by the entry Recreational $l_{0.1} *$ Post, is not significant at $p<0.05$. These results suggest that the disamenity effects purported by column (1) should be attributed to the space that marijuana dispensaries occupy, and not to the dispensaries themselves.

\subsection{Robustness Checks}

\subsubsection{Similar Outlets}

As a robustness check, we consider the effect that other establishments selling controlled substances may have on residential property values in columns (3) and (4) of Tables 18 and 19. Specifically, we make comparisons between the local amenity effects of recreational marijuana outlets and those of liquor stores and medical marijuana establishments. We choose these establishments because they all trade in government-regulated drugs. Should these outlets exhibit amenity effects vastly different from those found for recreational marijuana outlets upon controlling for location specific effects, then we may be concerned that our findings mischaracterize the process by which recreational marijuana outlets affect home value.

We first consider the amenity effects of medical marijuana establishments using a model identical to that from specification (2) in Tables 18 and 19 in column (3) of these two tables. This is an important step to take since, upon legalization of the sale of marijuana for recreation, many early recreational marijuana dispensaries were previously medical marijuana dispensaries. Similarly to our findings for retail marijuana outlets, we find some evidence for disamenity effects of medical marijuana dispensaries for very nearby single family homes, and amenity effects of these establishments on condominiums. However, we find no statistical evidence that 
the outlets themselves contribute to these amenity effects upon controlling for sales taking place after the opening of these medical marijuana outlets (represented by Medical $_{0.1} *$ Post), reflecting the conclusions from the exercise with recreational marijuana outlets.

Likewise, in column (4) we perform the same robustness test but for establishments of liquor stores. Just like with medical and recreational marijuana outlets, the locations of liquor stores serve as disamenities for single family homes and amenities for condominiums; however, these results largely disappear upon controlling for the opening periods of the liquor stores. We conclude that recreational marijuana outlets appear to exhibit amenity effects in line with medical marijuana outlets and liquor stores.

\subsubsection{Counterfactual Experiment}

Finally, we perform a counterfactual experiment as a robustness check on the validity of the results of the post-treatment effect analyzed in column (2) of Tables 18 and 19. To further separate the amenity effects of location from those of proximity to recreational marijuana outlets, we randomize the locations of the outlets to where any commercial real estate sales occurred during our sample period. The notion here is that, should the post-opening effects be significantly different from the locational effects associated with nearness of residential property to commercial space in the city, then there may be an argument for the amenity effects of recreational marijuana outlets. Likewise, should the estimated coefficients for Recreational $0.1 *$ Post from $_{0.1}$ column (2) of Tables 18 and 19 fall nearer the center of the distribution, then we can be more certain that the opening of recreational marijuana outlets is not having a significant effect on home sale prices. Significant predicted coefficients on Recreational $_{0.1} *$ Post in Figure 12, conversely, suggest that proximity to commercial space, regardless of use, is considered a (dis)amenity. 
To start, we allow for the coordinates of recreational marijuana outlets to take values associated with commercial real estate sales during the sample period. The models from column (2) of Tables 18 and 19 are then estimated, assuming the same opening periods and the randomized locations of the retail outlets. Coefficient estimates are reserved for Recreational ${ }_{0.1} *$ Post and Recreatopma; $;_{0.25} *$ Post for single family homes and condominiums, and the locations are again randomized for another pass. We simulate randomized locations of all recreational marijuana outlets 500 times to build a frequency distribution. These distributions are presented in Figure 12, along with the actual estimated post-treatment effects.

Figure 12 further confirms the hypothesis that proximity to commercial space is a (dis)amenity. Recreational $l_{0.1} *$ Post is significant at the $10 \%$ level for both single family homes and condominiums. This counterfactual experiment provides no evidence for the amenity effects of recreational marijuana themselves outlets on nearby home value.

\subsection{Conclusion}

Legalization of marijuana is controversial in the United States. Recent legalization of the substance in a few U.S. states has brought the debate over marijuana legalization into the spotlight, especially as legalization pertains to real estate markets, public health, and potential tax revenues.

In this paper, we considered the effect of the legalization of marijuana in Colorado in November 2012 and the following establishments of recreational marijuana dispensaries on nearby property values. The policy shock and subsequent dispensary establishments represent a natural experiment wherein the net effects of proximity to recreational drug dispensaries on property prices can be estimated. While simple hedonic model estimation suggests that the location of marijuana outlets near homes may be a disamenity, inspection of price gradients provides some evidence that 
Single Family Homes
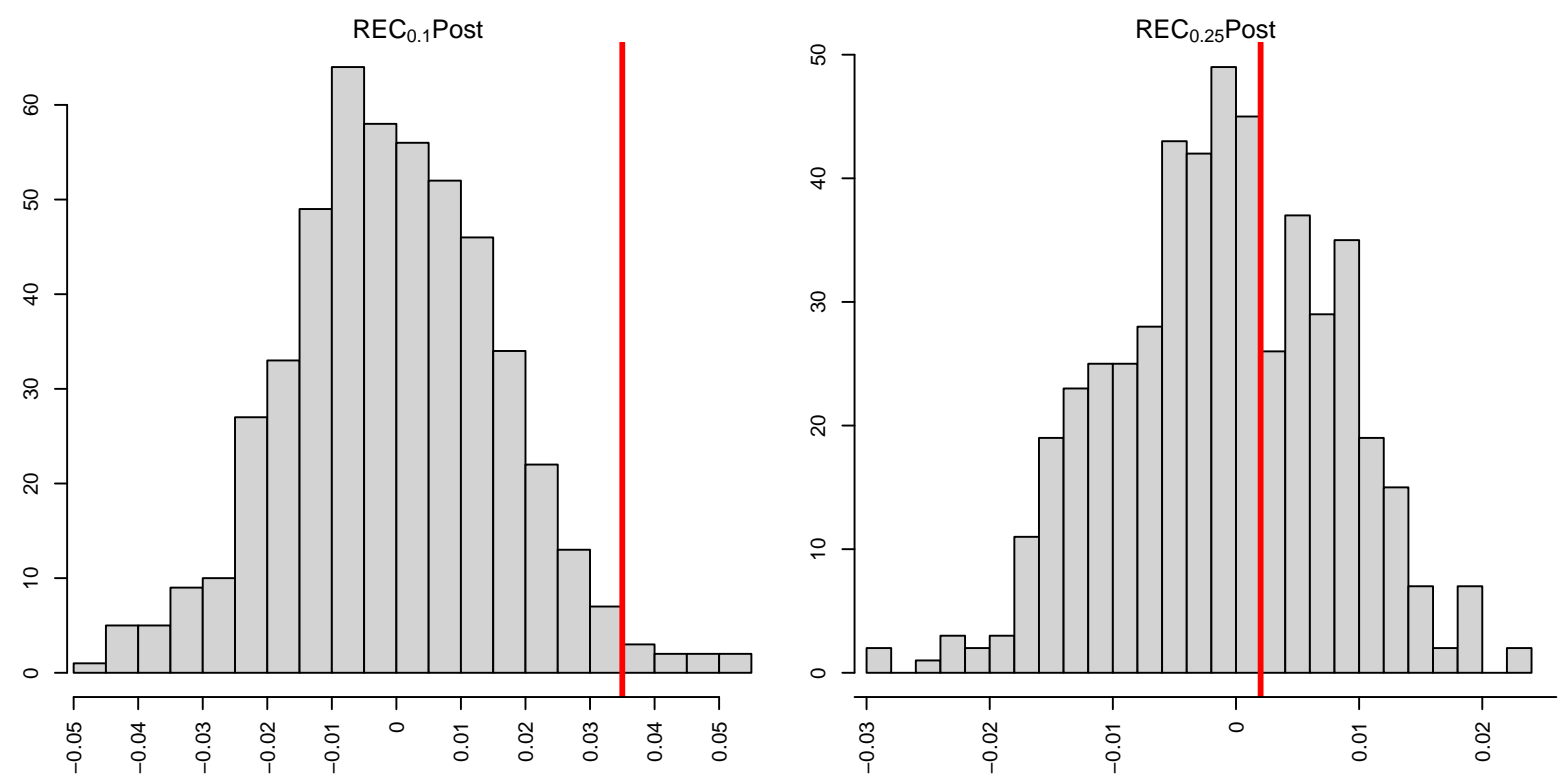

Condominiums
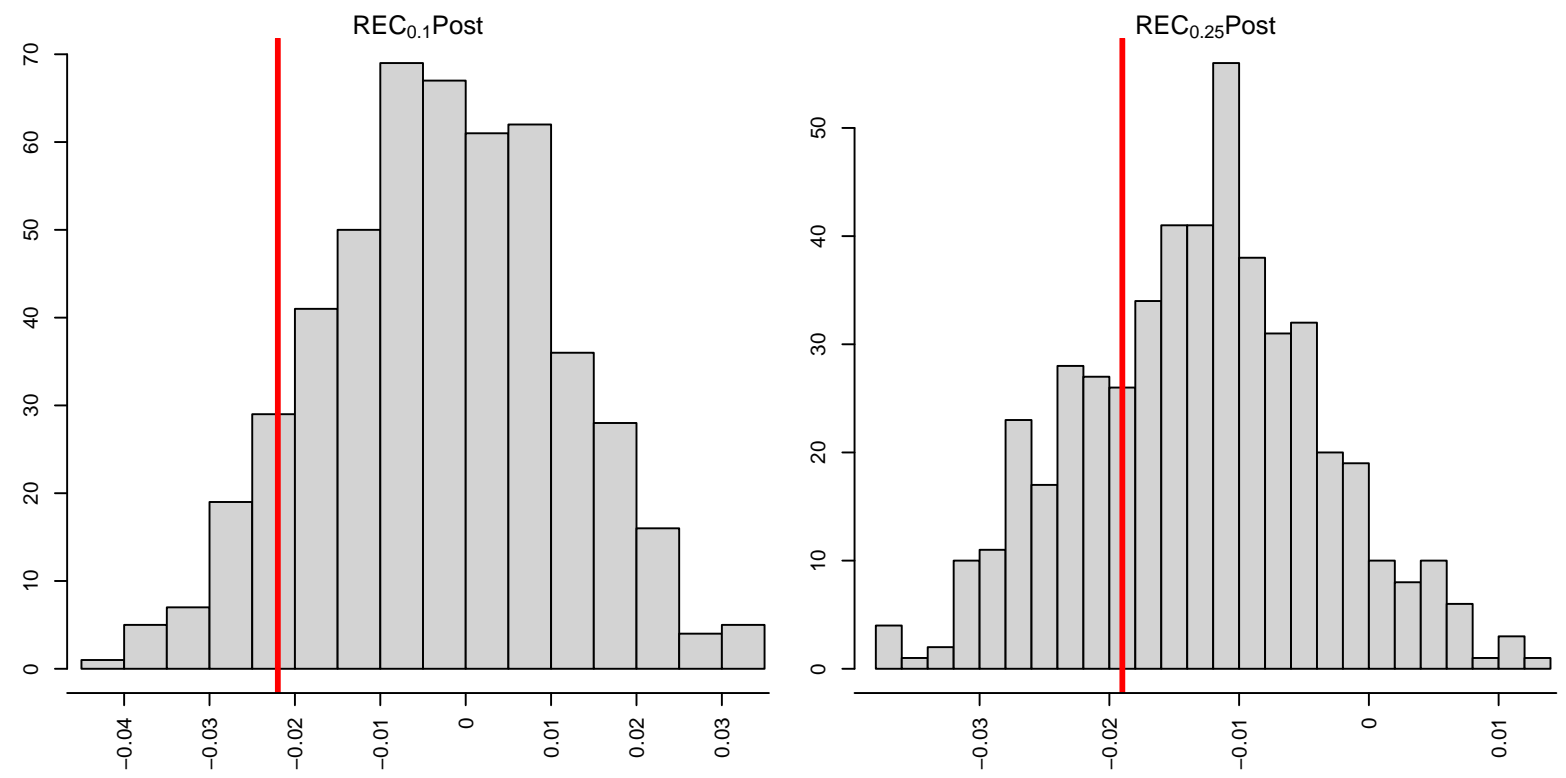

Figure 12: Histograms of Counterfactual Opening Estimates 
the hedonic model may be misattributing some of the effects of local neighborhood disamenities to retail marijuana dispensaries. Results from a difference-in-differences specification show little evidence that proximal access to recreational marijuana dispensaries in Denver affects property prices for homes very near new recreational marijuana dispensaries.

The legalization of marijuana in Denver provided competing forces over home prices which appear to have largely cancelled each other out. Marijuana legalization provides employment in a new industry, all else equal, leading to increased demand for housing. In addition to purveyors, consumers of marijuana may choose to move to cities where the sale and consumption of the substance is legal, further applying upward pressure to housing demand. However, home prices nearby marijuana businesses tend to be lower than Denver County's average home price. For this reason, possible disamenity effects associated with marijuana sale and those of lower property value locations need to be disentangled.

While the simple hedonic specification suggests very local disamenity effects for home sales near marijuana retail outlets, hinting that the negatives of legalization may outweigh the benefits of marijuana legalization for housing markets, controlling for the observation that marijuana outlets are setting up shop in disadvantaged locations demonstrates that the naive specification misattributes location disamenities to the outlet. For this reason, studies purporting that there is an association between the location of a marijuana dispensary and diminished home prices are simply describing correlation. Marijuana outlets are not causing lowered home prices, but are simply opening up shop in places where real estate is relatively cheap. On the other hand, studies demonstrating amenity effects related to retail marijuana outlets may be picking up rapid property price increases during the period, perhaps unrelated to the marijuana industry, and recent and historically high overvaluation of homes in the county. 
Future research on this topic will be very important as marijuana legalization becomes a hotter issue in more states. Furthermore, marijuana outlets are seeing shifts in how these infant businesses are being run, with many outlets in Denver focusing on rebranding the sale of the drug through changes in aesthetics of the stores and with the types of products being sold. As more data becomes available, either through continued pushes for legalization in the states, or expansion of the time series in states where the substance is already legal, the effects of marijuana outlets on home value may be further elucidated. 
Table 18: Impact of Marijuana Dispensary Establishment on Residential Property Value - Single Family Homes

\begin{tabular}{|c|c|c|c|c|}
\hline & \multicolumn{4}{|c|}{ Dependent variable: } \\
\hline & \multicolumn{4}{|c|}{$\ln ($ Price $)$} \\
\hline & $(1)$ & $(2)$ & $(3)$ & $(4)$ \\
\hline Recreational $_{0.1}$ & $\begin{array}{c}-0.059^{* * *} \\
(0.018)\end{array}$ & $\begin{array}{c}-0.076^{* * *} \\
(0.004)\end{array}$ & & \\
\hline Recreational $_{0.25}$ & $\begin{array}{c}-0.023^{*} \\
(0.010)\end{array}$ & $\begin{array}{c}-0.026^{* *} \\
(0.008)\end{array}$ & & \\
\hline Recreational $_{0.1} *$ Post & & $\begin{array}{c}0.034 \\
(0.049)\end{array}$ & & \\
\hline Recreational $_{0.25} *$ Post & & $\begin{array}{c}0.008 \\
(0.010)\end{array}$ & & \\
\hline Medical $_{0.1}$ & & & $\begin{array}{c}-0.053^{* * *} \\
(0.013)\end{array}$ & \\
\hline Medical $_{0.25}$ & & & $\begin{array}{l}-0.015 \\
(0.009)\end{array}$ & \\
\hline Medical $_{0.1} *$ Post & & & $\begin{array}{l}-0.004 \\
(0.014)\end{array}$ & \\
\hline Medical $_{0.25} *$ Post & & & $\begin{array}{l}-0.002 \\
(0.003)\end{array}$ & \\
\hline Alcohol $_{0.1}$ & & & & $\begin{array}{c}-0.054^{* * *} \\
(0.014)\end{array}$ \\
\hline Alcohol $_{0.25}$ & & & & $\begin{array}{l}-0.011 \\
(0.008)\end{array}$ \\
\hline Alcohol $_{0.1} *$ Post & & & & $\begin{array}{l}-0.007 \\
(0.033)\end{array}$ \\
\hline Alcohol $_{0.25} *$ Post & & & & $\begin{array}{l}-0.008 \\
(0.006) \\
\end{array}$ \\
\hline Home Attributes & $\mathrm{Y}$ & $\mathrm{Y}$ & $\mathrm{Y}$ & $\mathrm{Y}$ \\
\hline Tract-Year FE & $\mathrm{Y}$ & $\mathrm{Y}$ & $\mathrm{Y}$ & $\mathrm{Y}$ \\
\hline Observations & 13,457 & 13,457 & 13,457 & 13,457 \\
\hline $\mathrm{R}^{2}$ & 0.869 & 0.869 & 0.869 & 0.869 \\
\hline
\end{tabular}


Table 19: Impact of Marijuana Dispensary Establishment on Residential Property Value - Condominiums

\begin{tabular}{|c|c|c|c|c|}
\hline & \multicolumn{4}{|c|}{ Dependent variable: } \\
\hline & \multicolumn{4}{|c|}{$\ln ($ Price $)$} \\
\hline & (1) & (2) & (3) & (4) \\
\hline Recreational $_{0.1}$ & $\begin{array}{c}-0.044^{* *} \\
(0.020)\end{array}$ & $\begin{array}{c}0.111^{* * *} \\
(0.010)\end{array}$ & & \\
\hline Recreational $_{0.25}$ & $\begin{array}{l}-0.013 \\
(0.030)\end{array}$ & $\begin{array}{c}0.184^{* * *} \\
(0.006)\end{array}$ & & \\
\hline Recreational $_{0.1} *$ Post & & $\begin{array}{l}-0.022 \\
(0.020)\end{array}$ & & \\
\hline Recreational $_{0.25} *$ Post & & $\begin{array}{c}-0.019^{* * *} \\
(0.007)\end{array}$ & & \\
\hline Medical $_{0.1}$ & & & $\begin{array}{r}0.079^{* * *} \\
(0.007)\end{array}$ & \\
\hline Medical $_{0.25}$ & & & $\begin{array}{r}0.214^{* * *} \\
(0.008)\end{array}$ & \\
\hline Medical $_{0.1} *$ Post & & & $\begin{array}{c}0.006 \\
(0.012)\end{array}$ & \\
\hline Medical $_{0.25} *$ Post & & & $\begin{array}{c}0.002 \\
(0.006)\end{array}$ & \\
\hline Alcohol $_{0.1}$ & & & & $\begin{array}{c}0.083^{* * *} \\
(0.014)\end{array}$ \\
\hline Alcohol $_{0.25}$ & & & & $\begin{array}{c}0.236^{* * *} \\
(0.010)\end{array}$ \\
\hline Alcohol $_{0.1} *$ Post & & & & $\begin{array}{l}-0.002 \\
(0.022)\end{array}$ \\
\hline Alcohol $_{0.25} *$ Post & & & & $\begin{array}{c}-0.027^{* *} \\
(0.013) \\
\end{array}$ \\
\hline Home Attributes & Y & Y & Y & Y \\
\hline Tract-Year FE & Y & Y & Y & Y \\
\hline Observations & 6,686 & 6,686 & 6,686 & 6,686 \\
\hline $\mathrm{R}^{2}$ & 0.904 & 0.929 & 0.930 & 0.930 \\
\hline
\end{tabular}




\section{References}

Abbott, R. D., White, L. R., Ross, G. W., Masaki, K. H., Curb, J. D., and Petrovitch, H. (2004). Walking and dementia in physically capable elderly men. Jama, 292(12):1447-1453.

Anderson, D. M., Hansen, B., and Rees, D. I. (2013). Medical marijuana laws, traffic fatalities, and alcohol consumption. Journal of Law and Economics, 56(2):333-369.

Anderson, D. M., Rees, D. I., and Sabia, J. J. (2014). Medical marijuana laws and suicides by gender and age. American Journal of Public Health, 104(12):2369-2376.

Andreoni, J. and Petrie, R. (2008). Beauty, gender and stereotypes: Evidence from laboratory experiments. Journal of Economic Psychology, 29(1):73-93.

Armstrong, R. J. and Rodriguez, D. A. (2006). An evaluation of the accessibility benefits of commuter rail in eastern Massachusetts using spatial hedonic price functions. Transportation, 33(1):21-43.

Arth, M. (2009). The labors of Hercules: Modern solutions to 12 Herculean problems, volume 1. Golden Apples Media, Incorporated.

Baum-Snow, N. and Kahn, M. E. (2000). The effects of new public projects to expand urban rail transit. Journal of Public Economics, 77(2):241-263.

Bennett, K. P. and Mangasarian, O. L. (1992). Robust linear programming discrimination of two linearly inseparable sets. Optimization Methods and Software, $1(1): 23-34$.

Biddle, J. E. and Hamermesh, D. S. (1998). Beauty, productivity, and discrimination: Lawyers' looks and lucre. Journal of Labor Economics, 16(1):172-201. 
Boggess, L. N., Pérez, D. M., Cope, K., Root, C., and Stretesky, P. B. (2014). Do medical marijuana centers behave like locally undesirable land uses? Implications for the geography of health and environmental justice. Urban Geography, 35(3):315-336.

Brasington, D. (1999). Which measures of school quality does the housing market value? Journal of Real Estate Research, 18(3):395-413.

Brasington, D. (2009). Which measures of school quality does the housing market value? Journal of Real Estate Research.

Brasington, D. and Haurin, D. R. (2006). Educational outcomes and house values: A test of the value added approach. Journal of Regional Science, 46(2):245-268.

Brasington, D. M. (2007). Private schools and the willingness to pay for public schooling. Education, 2(2):152-174.

Brasington, D. M. and Hite, D. (2008). A mixed index approach to identifying hedonic price models. Regional Science and Urban Economics, 38(3):271-284.

Brooks, T. J., Humphreys, B. R., and Nowak, A. (2015). Strip clubs, "secondary effects," and property values.

Brown, G. M. and Pollakowski, H. O. (1977). Economic valuation of shoreline. The Review of Economics and Statistics, pages 272-278.

Buchanan, C., Koch, A., Wedderburn, M., Sieh, L., and Ho, S. (2007). Paved with gold-The real value of good street design. London, Commission for Architecture and the Built Environment.

Caputo, M. R. and Ostrom, B. J. (1994). Potential tax revenue from a regulated marijuana market a meaningful revenue source. American Journal of Economics and Sociology, 53(4):475-490. 
Caudill, S. B., Affuso, E., and Yang, M. (2015). Registered sex offenders and house prices: An hedonic analysis. Urban Studies, 52(13):2425-2440.

Chang, C.-C. and Lin, C.-J. (2011). Libsvm: a library for support vector machines. ACM Transactions on Intelligent Systems and Technology (TIST), 2(3):27.

Cheng, C., Mayer, W., and Mayer, Y. (2016). The effect of legalizing retail marijuana on housing values: Evidence from Colorado.

Cisneros, C. (2015). Value of walkable communities. PhD thesis, California State University, Sacramento.

Conklin, J. N., Diop, M., and Li, H. (2016). Contact high: The external effects of retail marijuana establishments on house prices.

Cortright, J. (2009). Walking the walk: How walkability raises home values in US cities.

Crost, B. and Guerrero, S. (2012). The effect of alcohol availability on marijuana use: Evidence from the minimum legal drinking age. Journal of Health Economics, 31(1):112-121.

Davis, L. W. (2011). The effect of power plants on local housing values and rents. Review of Economics and Statistics, 93(4):1391-1402.

Day, K., Boarnet, M., Alfonzo, M., and Forsyth, A. (2006). The Irvine-Minnesota inventory to measure built environments: Development. American Journal of Preventive Medicine, 30(2):144-152.

DiNardo, J. and Lemieux, T. (2001). Alcohol, marijuana, and american youth: the unintended consequences of government regulation. Journal of Health Economics, 20(6):991-1010. 
Espey, M. and Lopez, H. (2000). The impact of airport noise and proximity on residential property values. Growth and Change, 31(3):408-419.

Ewing, R. and Handy, S. (2009). Measuring the unmeasurable: Urban design qualities related to walkability. Journal of Urban Design, 14(1):65-84.

Felzenszwalb, P. F., Girshick, R. B., McAllester, D., and Ramanan, D. (2010). Object detection with discriminatively trained part-based models. IEEE Transactions on Pattern Analysis and Machine Intelligence, 32(9):1627-1645.

Figueroa, R. L., Zeng-Treitler, Q., Kandula, S., and Ngo, L. H. (2012). Predicting sample size required for classification performance. BMC Medical Informatics and Decision Making, 12(1):8.

Friedman, J., Hastie, T., and Tibshirani, R. (2001). The elements of statistical learning, volume 1. Springer Series in Statistics Springer, Berlin.

Gibbons, S. and Machin, S. (2008). Valuing school quality, better transport, and lower crime: Evidence from house prices. oxford review of Economic Policy, 24(1):99-119.

Gilderbloom, J. I., Riggs, W. W., and Meares, W. L. (2015). Does walkability matter? An examination of walkability's impact on housing values, foreclosures and crime. Cities, 42:13-24.

Hajrasouliha, A. and Yin, L. (2015). The impact of street network connectivity on pedestrian volume. Urban Studies, 52(13):2483-2497.

Hall, J. (2017). Does school district and municipality border congruence matter? Urban Studies, page 0042098015619868.

Hamermesh, D. S. (2006). Changing looks and changing "discrimination": The beauty of economists. Economics Letters, 93(3):405-412. 
Hamermesh, D. S. and Biddle, J. E. (1993). Beauty and the labor market. Technical report, National Bureau of Economic Research.

Hamermesh, D. S. and Parker, A. (2005). Beauty in the classroom: Instructors' pulchritude and putative pedagogical productivity. Economics of Education Review, 24(4):369-376.

Jaskiewicz, F. (2000). Pedestrian level of service based on trip quality. Transportation Research Circular.

Kilmer, B., Caulkins, J. P., Pacula, R. L., MacCoun, R. J., Reuter, P., et al. (2010). Altered state?: Assessing how marijuana legalization in California could influence marijuana consumption and public budgets. RAND Santa Monica, CA.

Kok, N. and Jennen, M. (2012). The impact of energy labels and accessibility on office rents. Energy Policy, 46:489-497.

Lansford, N. H. and Jones, L. L. (1995). Marginal price of lake recreation and aesthetics: an hedonic approach. Journal of Agricultural and Applied Economics, 27(01):212-223.

Leinberger, C. and Alfonzo, M. (2012). Walk this way: The economic promise of walkable places in metropolitan washington, dc. The Brookings Institution.

Levinson, J., Askeland, J., Becker, J., Dolson, J., Held, D., Kammel, S., Kolter, J. Z., Langer, D., Pink, O., Pratt, V., et al. (2011). Towards fully autonomous driving: Systems and algorithms. In Intelligent Vehicles Symposium (IV), 2011 IEEE, pages 163-168. IEEE.

Linden, L. and Rockoff, J. E. (2008). Estimates of the impact of crime risk on property values from megan's laws. The American Economic Review, 98(3):1103-1127. 
Linn, J. (2013). The effect of voluntary brownfields programs on nearby property values: Evidence from Illinois. Journal of Urban Economics, 78:1-18.

Litman, T. (2003). Economic value of walkability. Transportation Research Record: Journal of the Transportation Research Board, (1828):3-11.

Loughran, T. and McDonald, B. (2011). When is a liability not a liability? Textual analysis, dictionaries, and 10-ks. The Journal of Finance, 66(1):35-65.

Manaugh, K. and El-Geneidy, A. (2011). Validating walkability indices: How do different households respond to the walkability of their neighborhood? Transportation Research Part D: Transport and Environment, 16(4):309-315.

Matthews, J. W. and Turnbull, G. K. (2007). Neighborhood street layout and property value: The interaction of accessibility and land use mix. The journal of real estate finance and economics, 35(2):111-141.

Matykiewicz, P. and Pestian, J. (2012). Effect of small sample size on text categorization with support vector machines. In Proceedings of the 2012 Workshop on Biomedical Natural Language Processing, pages 193-201. Association for Computational Linguistics.

McCann, B. et al. (2000). Driven to spend; The impact of sprawl on household transportation expenses. Surface Transportation Policy Project and the Center for Neighborhood Technology, Chapter Three. See also "The Costs of Sprawl-Revisited, pages 6-7.

McMillen, D. P. and McDonald, J. (2004). Reaction of house prices to a new rapid transit line: Chicago's midway line, 1983-1999. Real Estate Economics, 32(3):463-486. 
Mobius, M. M. and Rosenblat, T. S. (2006). Why beauty matters. The American Economic Review, 96(1):222-235.

Mohan, A., Papageorgiou, C., and Poggio, T. (2001). Example-based object detection in images by components. IEEE Transactions on Pattern Analysis and Machine Intelligence, 23(4):349-361.

Naik, N., Kominers, S. D., Raskar, R., Glaeser, E. L., and Hidalgo, C. A. (2015). Do people shape cities, or do cities shape people? the co-evolution of physical, social, and economic change in five major us cities. Technical report, National Bureau of Economic Research.

Naik, N., Raskar, R., and Hidalgo, C. A. (2016). Cities are physical too: Using computer vision to measure the quality and impact of urban appearance. The American Economic Review, 106(5):128-132.

Nelson, J. P. (2004). Meta-analysis of airport noise and hedonic property values. Journal of Transport Economics and Policy (JTEP), 38(1):1-27.

Ours, J. C. and Williams, J. (2015). Cannabis use and its effects on health, education and labor market success. Journal of Economic Surveys, 29(5):993-1010.

Owen, N., Cerin, E., Leslie, E., Coffee, N., Frank, L. D., Bauman, A. E., Hugo, G., Saelens, B. E., Sallis, J. F., et al. (2007). Neighborhood walkability and the walking behavior of Australian adults. American journal of preventive medicine, $33(5): 387-395$.

Pacula, R. L. (1998). Does increasing the beer tax reduce marijuana consumption? Journal of Health Economics, 17(5):557-585.

Pivo, G. (2014). Walk score: The significance of 8 and 80 for mortgage default risk in multifamily properties. Journal of Sustainable Real Estate, 6(2):187-210. 
Pivo, G. and Fisher, J. D. (2011). The walkability premium in commercial real estate investments. Real Estate Economics, 39(2):185-2/19.

Pope, J. C. (2008a). Buyer information and the hedonic: the impact of a seller disclosure on the implicit price for airport noise. Journal of Urban Economics, 63(2):498-516.

Pope, J. C. (2008b). Do seller disclosures affect property values? Buyer information and the hedonic model. Land Economics, 84(4):551-572.

Pope, J. C. (2008c). Fear of crime and housing prices: Household reactions to sex offender registries. Journal of Urban Economics, 64(3):601-614.

Rauterkus, S. Y. and Miller, N. (2011). Residential land values and walkability. Journal of Sustainable Real Estate, 3(1):23-43.

Rosen, S. (1974). Hedonic prices and implicit markets: product differentiation in pure competition. Journal of Political Economy, 82(1):34-55.

Rosenblat, T. S. (2008). The beauty premium: Physical attractiveness and gender in dictator games. Negotiation Journal, 24(4):465-481.

Schiilkopf, B. (2001). The kernel trick for distances. In Advances in Neural Information Processing Systems 13: Proceedings of the 2000 Conference, volume 13, page 301. MIT Press.

Smith, F. W. (1968). Pattern classifier design by linear programming. IEEE Transactions on Computers, 100(4):367-372.

Song, Y. and Knaap, G.-J. (2003). New urbanism and housing values: A disaggregate assessment. Journal of Urban Economics, 54(2):218-238.

Song, Y. and Knaap, G.-J. (2004). Measuring the effects of mixed land uses on housing values. Regional Science and Urban Economics, 34(6):663-680. 
Southworth, M. (2005). Designing the walkable city. Journal of Urban Planning and Development, 131(4):246-257.

Taddy, M. (2013). Multinomial inverse regression for text analysis. Journal of the American Statistical Association, 108(503):755-770.

Troy, A. and Grove, J. M. (2008). Property values, parks, and crime: A hedonic analysis in Baltimore, MD. Landscape and Urban Planning, 87(3):233-245.

Tu, C. C. and Eppli, M. J. (1999). Valuing new urbanism: The case of Kentlands. Real Estate Economics, 27(3):425-451.

Tu, C. C. and Eppli, M. J. (2001). An empirical examination of traditional neighborhood development. Real Estate Economics, 29(3):485-501.

Zhu, X. and Lee, C. (2008). Walkability and safety around elementary schools: Economic and ethnic disparities. American Journal of Preventive Medicine, $34(4): 282-290$. 